\title{
55-TW magnetically insulated transmission-line system: Design, simulations, and performance
}

\author{
W. A. Stygar, ${ }^{1}$ P. A. Corcoran, ${ }^{2}$ H. C. Ives, ${ }^{3}$ R. B. Spielman, ${ }^{4}$ J. W. Douglas, ${ }^{2}$ B. A. Whitney, ${ }^{2}$ M. A. Mostrom,${ }^{5}$ \\ T. C. Wagoner, ${ }^{4}$ C. S. Speas, ${ }^{1}$ T. L. Gilliland, ${ }^{4}$ G. A. Allshouse, ${ }^{1}$ R. E. Clark,${ }^{6}$ G. L. Donovan, ${ }^{1}$ T. P. Hughes, ${ }^{1}$ \\ D. R. Humphreys, ${ }^{1}$ D. M. Jaramillo, ${ }^{1}$ M. F. Johnson, ${ }^{7}$ J. W. Kellogg, ${ }^{1}$ R. J. Leeper, ${ }^{1}$ F. W. Long, ${ }^{1}$ T. H. Martin, ${ }^{1}$
}

T. D. Mulville, ${ }^{1}$ M. D. Pelock, ${ }^{1}$ B. P. Peyton, ${ }^{4}$ J. W. Poukey, ${ }^{1}$ J. J. Ramirez, ${ }^{1}$ P. G. Reynolds, ${ }^{7}$ J. F. Seamen, ${ }^{1}$ D. B. Seidel, ${ }^{1}$

A. P. Seth, ${ }^{1}$ A. W. Sharpe,${ }^{1}$ R. W. Shoup, ${ }^{8}$ J. W. Smith, ${ }^{1}$ D. M. Van De Valde, ${ }^{3}$ and R. W. Wavrik ${ }^{1}$

${ }^{1}$ Sandia National Laboratories, Albuquerque, New Mexico 87185, USA

${ }^{2}$ L-3 Communications, Pulse Sciences, San Leandro, California 94577, USA

${ }^{3} E G \& G$, Albuquerque, New Mexico 87107, USA

${ }^{4}$ Ktech Corporation, Albuquerque, New Mexico 87123, USA

${ }^{5}$ Mission Research Corporation, Albuquerque, New Mexico 87110 USA

${ }^{6}$ Voss Scientific LLC, Albuquerque, New Mexico 87108, USA

${ }^{7}$ Team Specialty Products Corporation, Albuquerque, New Mexico 87123, USA

${ }^{8}$ ITT Corporation, Albuquerque, New Mexico 87110, USA

(Received 5 April 2009; published 7 December 2009)

We describe herein a system of self-magnetically insulated vacuum transmission lines (MITLs) that operated successfully at $20 \mathrm{MA}, 3 \mathrm{MV}$, and $55 \mathrm{TW}$. The system delivered the electromagnetic-power pulse generated by the $Z$ accelerator to a physics-package load on over $1700 Z$ shots. The system included four levels that were electrically in parallel. Each level consisted of a water flare, vacuum-insulator stack, vacuum flare, and 1.3-m-radius conical outer MITL. The outputs of the four outer MITLs were connected in parallel by a 7.6 -cm-radius 12-post double-post-hole vacuum convolute. The convolute added the currents of the four outer MITLs, and delivered the combined current to a single 6-cm-long inner MITL. The inner MITL delivered the current to the load. The total initial inductance of the stack-MITL system was $11 \mathrm{nH}$. A 300-element transmission-line-circuit model of the system has been developed using the TL code. The model accounts for the following: (i) impedance and electrical length of each of the 300 circuit elements, (ii) electron emission from MITL-cathode surfaces wherever the electric field has previously exceeded a constant threshold value, (iii) Child-Langmuir electron loss in the MITLs before magnetic insulation is established, (iv) MITL-flow-electron loss after insulation, assuming either collisionless or collisional electron flow, (v) MITL-gap closure, (vi) energy loss to MITL conductors operated at high lineal current densities, (vii) time-dependent self-consistent inductance of an imploding $z$-pinch load, and (viii) load resistance, which is assumed to be constant. Simulations performed with the TL model demonstrate that the nominal geometric outer-MITL-system impedance that optimizes overall performance is a factor of $\sim 3$ greater than the convolute-load impedance, which is consistent with an analytic model of an idealized MITL-load system. Power-flow measurements demonstrate that, until peak current, the $Z$ stack-MITL system performed as expected. TL calculations of the peak electromagnetic power at the stack, stack energy, stack voltage, outer-MITL current, and load current, as well as the pinch-implosion time, agree with measurements to within 5\%. After peak current, TL calculations and measurements diverge, which appears to be due in part to the idealized pinch model assumed by TL. The results presented suggest that the design of the $Z$ accelerator's stack-MITL system, and the TL model, can serve as starting points for the design of stack-MITL systems of future superpower accelerators.

DOI: 10.1103/PhysRevSTAB.12.120401

\section{INTRODUCTION}

The original $Z$ pulsed-power accelerator [1-10] was designed to drive $z$-pinch loads for inertial-confinementfusion, radiation-effects, radiation-physics, astrophysics, and other high-energy-density-physics experiments. $Z$ was also designed to serve as a testing facility for pulsedpower research required to develop future, higher-current drivers. $Z$ was subsequently adapted to produce a shaped current pulse for material-dynamics and equation-of-state experiments.
PACS numbers: 84.70.+p, 84.30.-r, 07.50.-e, 07.55.-w

As indicated by Fig. 1, $Z$ was contained within a 33-mdiameter tank with concentric oil, water, and vacuum sections. The accelerator consisted of 36 pulsed-power modules that were electrically in parallel. Each module delivered an electromagnetic-power pulse to the centrally located vacuum section. This section consisted of a fourlevel vacuum-insulator stack, a four-level system of selfmagnetically insulated vacuum transmission lines (MITLs), and the physics package that served as the intended load of the accelerator [1-10]. The insulator stack 


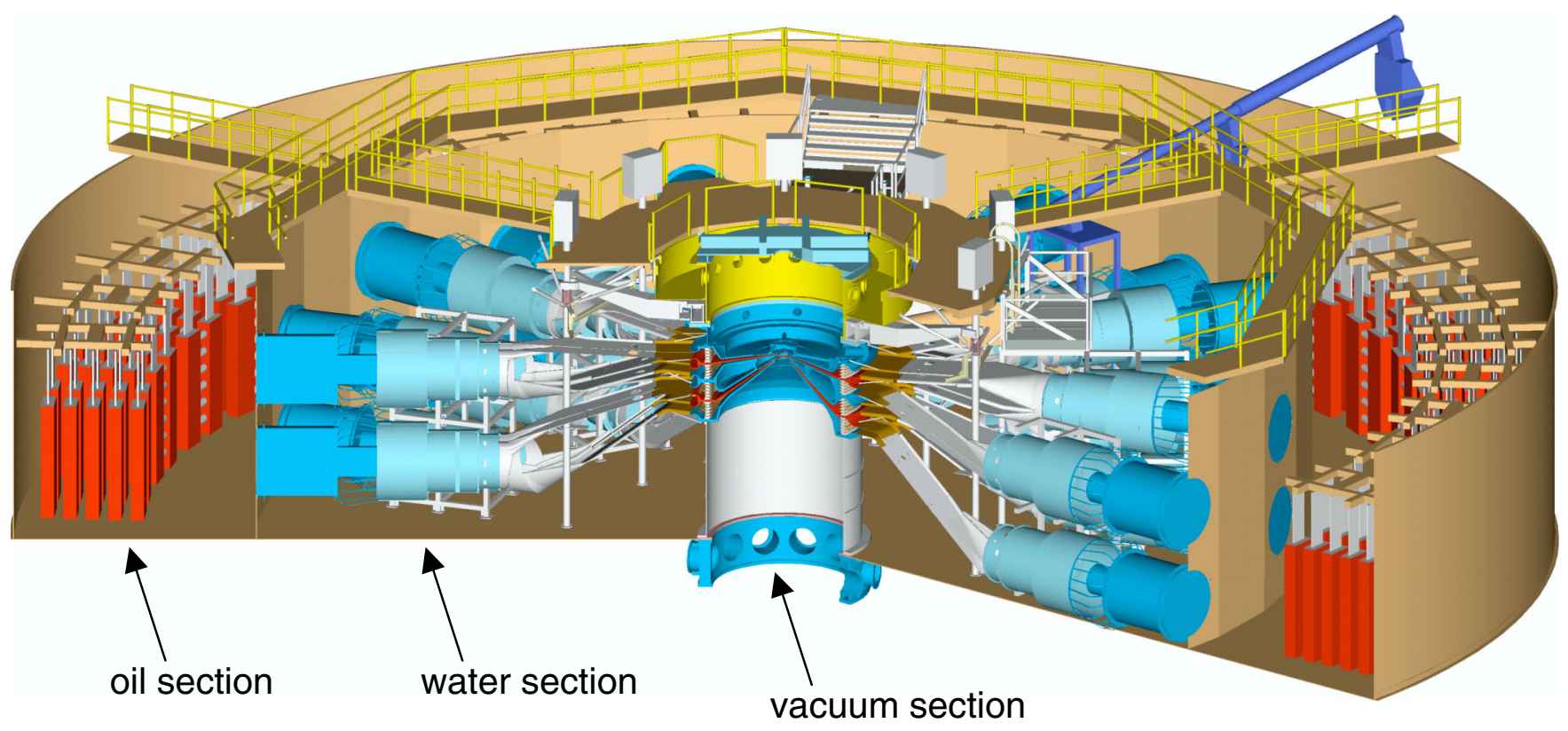

FIG. 1. (Color) Cross-sectional view of the $Z$ pulsed-power accelerator [1-10]. The outer diameter of the accelerator was $33 \mathrm{~m}$.

was the hermetic interface that separated the vacuum region from the rest of the accelerator. Nine pulsed-power modules were connected to each of the four levels of the stack-MITL system.

The design of the $Z$ accelerator's stack-MITL system was based on the successful designs [11-16] developed by Spielman and co-workers $[11,15,16]$ and Corcoran and colleagues [12-14] for the Proto-II [11,12,17-20] and Saturn [13-16,21,22] accelerators. The Proto-II stackMITL system delivered $\sim 5$ MA to a load; the Saturn system, which is still in operation, delivers $\sim 8$ MA.

$Z$ was operated from September 1996 until July 2006. Over this period more than 1700 shots were successfully taken on $Z$; data acquired on these shots have been published in 200 peer-reviewed journal articles. Most of the shots delivered a 20-MA, 3-MV, 55-TW electromagneticpower pulse to the stack-MITL system, and $2 \mathrm{MJ}$ of electromagnetic energy to the physics-package load for the experiments listed above. The original goal of the $Z$ accelerator was to produce a $1.5-\mathrm{MJ}$ pulse of thermal $x$ rays radiated by a $z$-pinch load. $Z$ met this goal on its 26 th shot, and subsequently produced as much as $2 \mathrm{MJ}[1,9,10]$.

In this article we describe the design of the $Z$ accelerator's stack-MITL system, and present a detailed transmission-line-circuit model of the system. The model has been developed using the TL transmission-line-circuit code [23]. (An earlier version of the TL model served as the primary $Z$ stack-MITL-system design tool $[2,9]$.) We also compare measurements of the stack-MITL-system's performance with the model's calculations. The results presented herein suggest that the design of the system, and the TL model, can serve as starting points for the design of stack-MITL systems of future superpower accelerators
$[24,25]$. The TL model complements other tools that can be used to design a MITL system, such as the MITL model developed by Martin, Savage, Gilmore, and Pointon [26].

When operated at a sufficiently high voltage, a MITL experiences space-charge-limited emission of electrons from the MITL's cathode electrode. When the bound current carried by the MITL's anode electrode is sufficiently high, the resulting magnetic field in the vacuum gap inhibits most of the emitted electrons from striking the anode; i.e., the transmission line becomes selfmagnetically insulated. The electrons $\mathbf{E} \times \mathbf{B}$ drift in the direction of the power flow, and are referred to as MITLflow electrons. MITLs are commonly used in pulsed-power accelerators to transmit electromagnetic power and energy to a load. Since a MITL operates under vacuum, use of a MITL requires a vacuum-insulator stack that separates the vacuum region from the rest of the accelerator.

Future multiterawatt pulsed-power accelerators are likely to include a stack-MITL system. Given the emission and subsequent flow of electrons in a MITL, and possible electron emission from the insulator-stack components, a future system might best be designed using particle-in-cell (PIC) simulations. Given the significant investment of resources that would be required to build a future stackMITL system, and hence the importance of knowing how well such a system would perform before it is fabricated, a future system might best be designed using 3D PIC simulations that model the system's entire radial, axial, and azimuthal extent.

Ideally, such simulations would have throughout sufficient spatial and temporal resolutions, and a sufficient number of particles per cell, to model correctly all electron effects of interest, such as the effects of geometric transi- 
tions, impedance transitions, and instabilities in the electron flow. It would also be desirable for such simulations to model nonideal conditions that are often present in a MITL. These conditions include the following: (i) the presence of anode and cathode plasmas; (ii) the presence of neutrals that expand from electrode surfaces and are subsequently ionized; (iii) the presence of particles that are vaporized and ionized; (iv) nonuniformities in the densities, temperatures, and velocities of the electrode plasmas, neutrals, and particles; (v) imperfect vacuum in the anode-cathode gap; (vi) anode-cathode-gap asymmetries; (vii) drive-voltage asymmetries; (viii) a voltage prepulse that early in time desorbs neutrals and particles from the electrode surfaces; (ix) electromagnetic radiation from the load and other plasmas in the system; (x) imperfect current contacts between MITL-electrode components, etc. In addition, the simulations would be capable of being repeated quickly to allow many iterations, in a reasonable period of time, toward an optimum stack-MITL-system design.

Since such simulations have not yet been possible, the design of the $Z$ accelerator's stack-MITL system was developed using a number of computational tools, each of which addressed a different component or aspect of the system [1-10]. As mentioned above, one of the tools was a TL circuit model of the entire stack-MITL system [2,9].

In this article, we describe an improved version of the TL model. The model has been developed using the TL code [23], but could also have been developed using other advanced circuit codes, such as BERTHA [27] and SCREAMER [28,29].

The present article is organized as follows. The design of the $Z$ stack-MITL system is described in Sec. II. The TL model of the system, and effects of various assumptions made by the model, are discussed in Sec. III.

Sections II and III outline the design of the stack-MITL system that was used for all of the shots taken on the $Z$ accelerator. In Sec. IV, we explore the performance of two alternate MITL-system designs that were considered during the design of $Z$. In Sec. V, we compare TL-model calculations with data taken on Z. In Sec. VI, we present suggestions for future work.

Auxiliary information is presented in three appendices. Appendix A discusses the energy-conservation error of the TL simulations described in this article. Appendix B develops an analytic model of an idealized MITL-load system, and demonstrates that under the conditions assumed, the power delivered to the load is maximized when the ratio of the geometric MITL impedance (which we define to be the impedance in the absence of electron emission, electron flow, and gap closure) to that of the load is $\sim 2$. (The presence of gap closure increases this ratio.) Appendix C defines an effective pinch current, and an effective pinchimplosion time, which are used to facilitate comparisons of simulation results.

\section{DESIGN OF THE Z-ACCELERATOR STACK-MITL SYSTEM}

A cross-sectional view of the $Z$ accelerator's stackMITL system is presented by Fig. 2. The central region of the system is detailed by Fig. 3. As suggested by the figures, the system comprised the following components: (i) four water flares, (ii) four vacuum-insulator stacks, (iii) four vacuum flares, (iv) four conical outer MITLs, (v) a double-post-hole vacuum convolute, (vi) an inner MITL, and (vii) the physics package that served as the intended load of the accelerator. Figures 2 and 3 illustrate a $z$-pinch load with a 2-cm length and 2-cm initial radius.

As suggested by Fig. 2, the four stack-MITL levels were labeled A, B, C, and D. The levels were electrically in parallel. The water-insulated bi-plate transmission lines shown in Fig. 2 delivered power from the $Z$ accelerator's 36 modules to the stack-MITL system. The impedance of each of the 36 water lines was $4.32 \Omega$. The water flares connected the water lines to the stack electrodes. The Aand B-level stacks each included five Rexolite insulator rings, each of which was $5.715-\mathrm{cm}$ thick. Four anodizedaluminum grading rings separated the five insulators. The C- and D-level stacks each included six insulator and five grading rings. Each of the C- and D-level stacks included within the water flare a field shaper (which had a circular cross section) to improve the uniformity of the voltage applied to the six insulator rings. The outer radius of the insulator rings (that had a cylindrical outer surface) was $1.68 \mathrm{~m}$.

The insulator-stack design is described in more detail in Refs. [2,4-7,9]. Measured stack-flashover probabilities were consistent with a statistical model of insulator flashover [30], as demonstrated by Table II of Ref. [30].

A vacuum flare connected each of the four stacks to an outer MITL. Two-dimensional (2D) electrostatic [6] and electromagnetic [5] calculations were used to design the flares. The calculations were used to minimize the inductance of the flares with the constraint that there be no significant emission of electrons from the stack's grading rings. The calculations assumed that anodized aluminum does not emit electrons at electric fields less than $300 \mathrm{kV} / \mathrm{cm}$ [31]. We designed the stack-MITL system to prevent significant electron emission from the grading rings, since such emission would have caused the voltage distribution across the stack's insulator rings to become nonuniform [5]. The 2D electromagnetic simulations described by Mostrom and co-workers in Ref. [5] demonstrate that the nonuniformity could have become as large as $50 \%$, which would have significantly increased the stackflashover probability [7,30,32].

We define the outer MITLs to be those located upstream of the double-post-hole vacuum convolute. The outer radius of the outer MITLs was nominally $1.3 \mathrm{~m}$. At a radius of $1 \mathrm{~m}$, the geometric impedances of the A-, B-, C-, and Dlevel MITLs were 1.98, 2.02, 2.74, and $2.73 \Omega$, respec- 


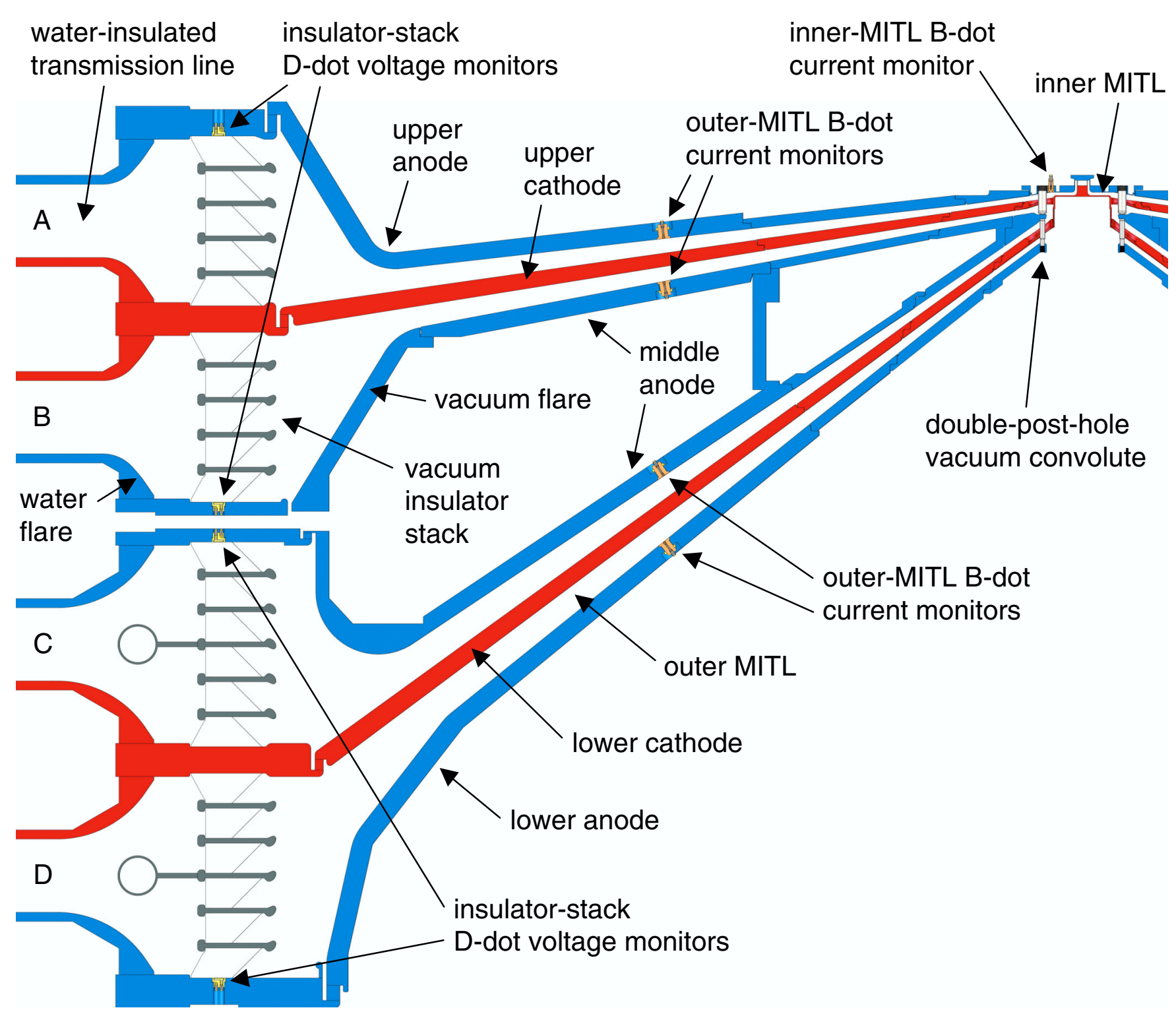

FIG. 2. (Color) Cross-sectional view of the insulator stack and magnetically insulated transmission lines (MITLs) of the $Z$ pulsedpower accelerator [1,2,4-10]. This view shows the locations of the stack, outer-MITL, and inner-MITL monitors.

tively. At a $10-\mathrm{cm}$ radius, each of the four MITLs had a 1$\mathrm{cm}$ anode-cathode gap; i.e., a geometric impedance of $6 \Omega$.

At a $7.6-\mathrm{cm}$ radius, the outputs of the four outer MITLs were connected in parallel by the convolute [1,2,4,916,33-43]. As suggested by Fig. 3, the convolute included 12-upper and 12-lower posts that connected the MITL anodes together; the convolute also connected the MITL cathodes together. Both the upper and lower posts were equally spaced on a $7.6-\mathrm{cm}$ radius. The convolute added the currents of the four outer MITLs, and delivered the combined current to an inner MITL. We define the inner MITL to be that which is located downstream of the convolute. The 6-cm-long inner MITL delivered the combined current to the load. The anode-cathode gap of the inner MITL's radial-transmission-line section was $6 \mathrm{~mm}$.
All of the outer-MITL, vacuum-convolute, and innerMITL cathode electrodes were fabricated from stainlesssteel-alloy 304L [4]. All of the anode electrodes inside a $\sim 0.6-\mathrm{m}$ radius were also $304 \mathrm{~L}$ [4]. Outside a $\sim 0.6-\mathrm{m}$ radius, the MITL anodes were fabricated from aluminum-alloy 6061-T6 [4] Stainless and aluminum were chosen in part because they are readily available, and have low outgassing rates and low physical-surface areas [44-47]. (Although outgassing depends strongly on previous history and surface preparation, compilations consistently rank stainless and aluminum with the best vacuum-system materials [44-47].) Stainless was chosen for all the components inside a $\sim 0.6-\mathrm{m}$ radius because its mass density is greater by a factor of 3 than that of aluminum, which reduces the depth of material that can 


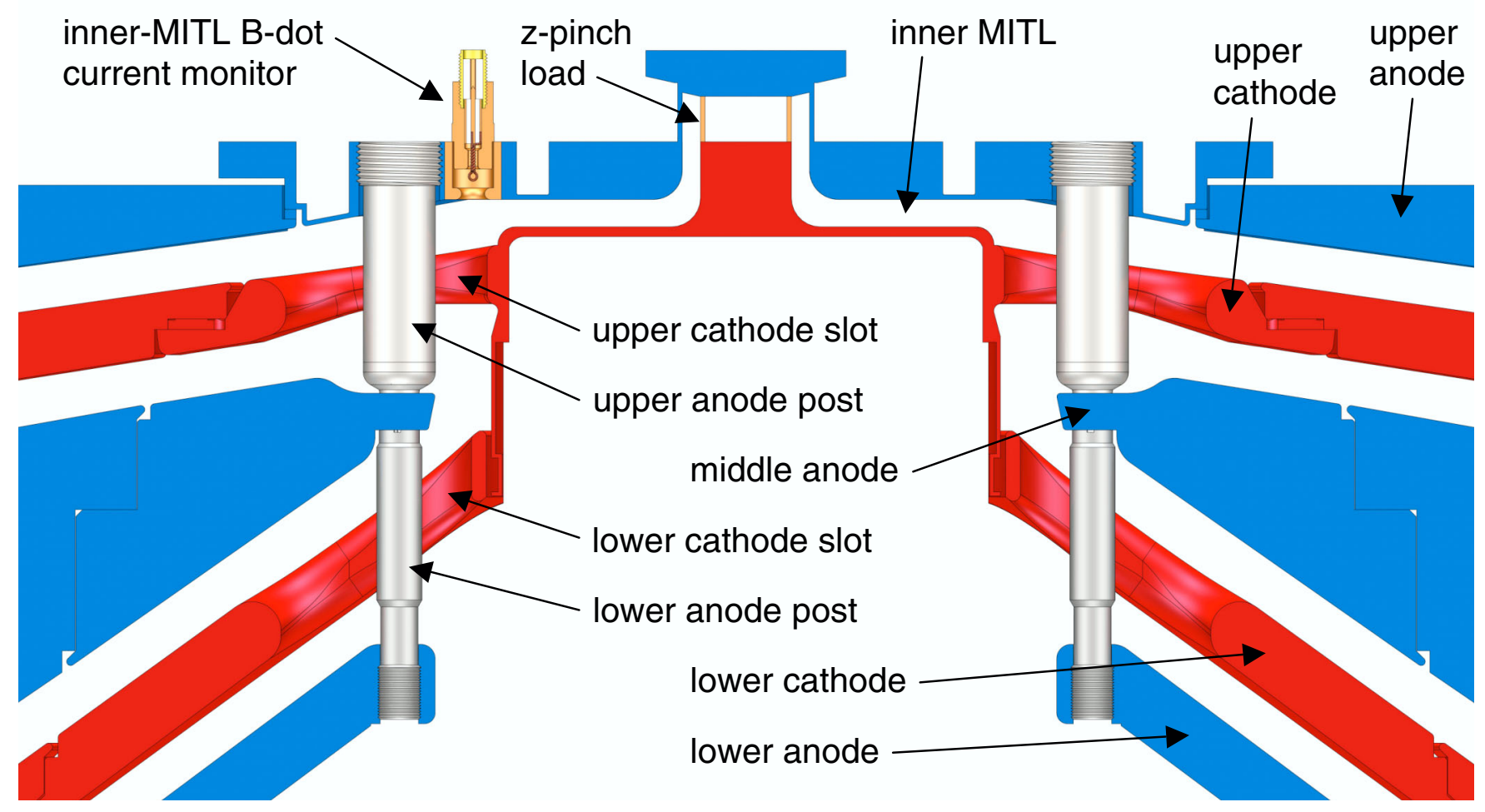

FIG. 3. (Color) Cross-sectional view of the double-post-hole convolute, inner MITL, and z-pinch load.

be damaged by electron impact and occasional arcs. Stainless also gives stable electrodes and has other superior high-voltage properties [48]. Reference [48] reports that stainless-steel-alloy 304 is widely used in high-voltage applications; 304L was selected instead because it is a superior material for the fabrication of large weldments. Aluminum was chosen for the anode electrodes outside a $\sim 0.6$-m radius, where the anode-cathode gaps were large, to keep the total weight of the MITL system less than the 10-ton capacity of the overhead bridge crane [4].

The design of the $Z$ accelerator's convolute and inner MITL were developed empirically on the Proto-II, DoubleEagle, Saturn, and $Z$ accelerators [1,2,4,9-16,33,34]. The performance of the convolute and inner MITL has been studied theoretically using 3D fully electromagnetic PIC simulations [35-43].

A diagnostic package [49] was developed to monitor the electrical performance of the $Z$ stack-MITL system. The package consisted of 62 gauges: three current and six voltage monitors that were fielded on each of the accelerator's four insulator stacks, six current monitors on each of the accelerator's four outer MITLs, and two current monitors on the accelerator's inner MITL. The inner-MITL monitors were located $6 \mathrm{~cm}$ from the axis of the load. We assume herein that the current measured at the inner-MITL location was a good approximation to the $z$-pinch-load current. The locations of several of the monitors are indicated by Figs. 2 and 3 .

\section{CIRCUIT MODEL OF THE Z-ACCELERATOR STACK-MITL SYSTEM}

A block diagram of the TL transmission-line-circuit model of the $Z$ accelerator's stack-MITL system is presented by Fig. 4. Each block is modeled using a number of transmission-line-circuit elements; approximately 300 elements are used for the entire model. The impedance $Z_{b}=$ $0.48 \Omega$, since nine parallel $4.32-\Omega$ water-insulated bi-plate transmission lines drove each of the four levels. TL models the implosion of the $z$-pinch load in a self-consistent manner, assuming the pinch is an infinitely thin and perfectly stable cylindrical foil [i.e., a zero-dimensional (OD) foil] that is driven by the load current.

$Z$ 's 36 modules launched 36 forward-going power pulses that drove the stack-MITL system. Given the forwardgoing power pulses, and the impedance of the accelerator's water-insulated transmission lines, the highest load current that could be achieved was determined to a large extent by the total initial inductance of the stack-MITL system. The inductances of the stack-MITL-system components are listed in Table I. When the load was a $z$ pinch, the peak load current was also determined by the time-dependent inductance of the imploding pinch load.

The TL model accounts for the following: (i) transmission-line impedance and electrical length of each of the 300 circuit elements of the model, (ii) electron emission from MITL cathodes wherever the electric 


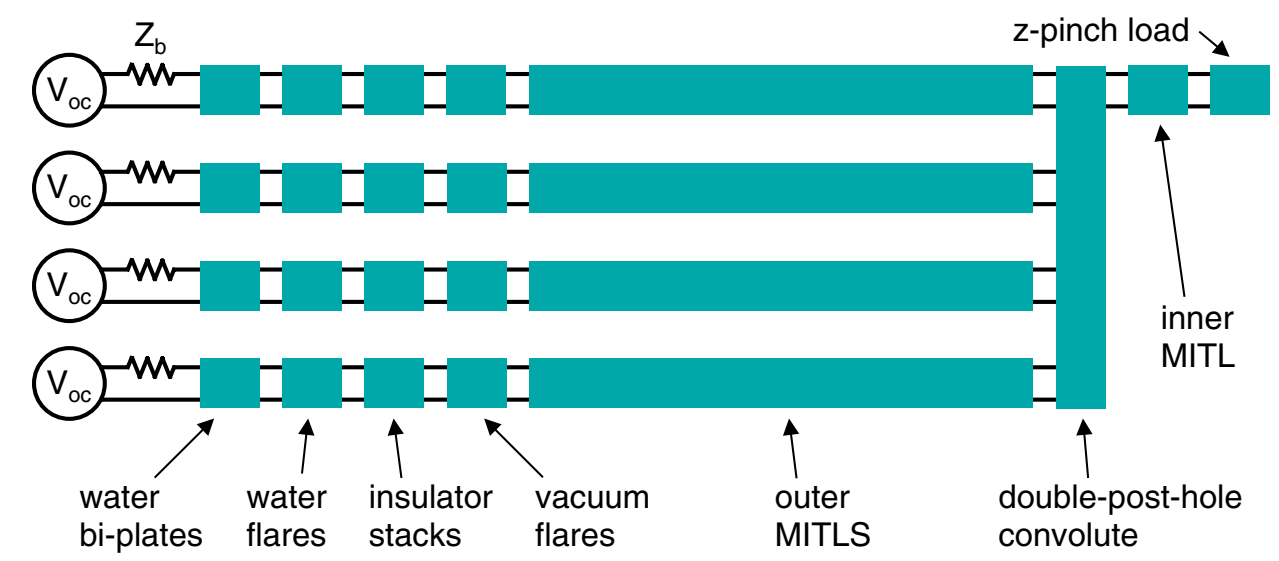

FIG. 4. (Color) Block diagram of the TL transmission-line-circuit model of the $Z$ stack-MITL system. $V_{\text {oc }}$ is the open-circuit voltage; $Z_{b}$ is the impedance of the set of nine parallel water-insulated bi-plate transmission lines that drove each level, and was equal to $0.48 \Omega$.

field has previously exceeded a constant threshold value; (iii) Child-Langmuir electron loss in the MITLs before magnetic insulation is established; (iv) loss of MITLflow-electron current after insulation, assuming either collisionless or collisional electron flow, (v) closure of the MITL's anode-cathode gaps at a constant rate; (vi) energy loss to conductors operated at high lineal current densities; (vii) time-dependent self-consistent inductance of an imploding 0D $z$-pinch load, and (viii) load resistance, which is assumed to be constant.

Table II describes seven versions of the TL model of the $Z$ stack-MITL system. The versions, labeled A through G, are used to quantify effects of the various assumptions made by the model. The calculated results given by the different versions are summarized by Table III. The results assume that the load is a $z$ pinch with a $2-\mathrm{cm}$ height, $2-\mathrm{cm}$

TABLE I. Inductances of the components of the $Z$-accelerator stack-MITL system. The inductances assume that the fractions of the total outer-MITL current that flowed in levels A, B, C, and $\mathrm{D}$ were $0.28,0.27,0.23$, and 0.22 , respectively. We define the inductance of a water flare to be that due to the impedance of the flare that is in excess of the impedance of the set of nine parallel bi-plate transmission lines that drove each level. For each of the other components, the inductance given is the total inductance, without any correction. The initial load inductance is that for a $z$-pinch load with a $2-\mathrm{cm}$ height, 2 -cm initial radius, and $2.5-\mathrm{cm}$ radius outer electrode with nine diagnostic slots.

\begin{tabular}{lc}
\hline \hline Component & Inductance \\
\hline A, B, C, and D water flares in parallel & $0.78 \mathrm{nH}$ \\
A, B, C, and D insulator stacks in parallel & $0.81 \mathrm{nH}$ \\
A, B, C, and D vacuum flares in parallel & $2.31 \mathrm{nH}$ \\
A, B, C, and D outer MITLs in parallel & $2.93 \mathrm{nH}$ \\
Double-post-hole convolute & $1.28 \mathrm{nH}$ \\
Inner MITL & $1.87 \mathrm{nH}$ \\
$z$-pinch load at $t=0$ & $1.11 \mathrm{nH}$ \\
Total & $11.09 \mathrm{nH}$ \\
\hline \hline
\end{tabular}

initial radius, and 4.27-mg total mass. This was the baseline load of the $Z$ accelerator.

As discussed in Appendix A, the energy-conservation error of the TL simulations summarized by Table III, and all the other TL simulations describe in this article, is less than $0.5 \%$.

\section{A. Transmission-line impedances and electrical lengths}

TL-model version A accounts only for the transmissionline impedance and electrical length of each of the 300 circuit elements. The inductance $L$ and capacitance $C$ of an element are given by

$$
\begin{aligned}
& L=Z_{0} \tau, \\
& C=\frac{\tau}{Z_{0}},
\end{aligned}
$$

where $Z_{0}$ is the geometric impedance of the element and $\tau$ is its electrical length. Version A assumes there is no electron emission from the MITL cathodes, and therefore ignores all energy-loss mechanisms that originate as electron emission. Version A ignores all other energy-loss mechanisms as well.

\section{B. Electron loss before insulation is established}

Version B assumes electrons are emitted from the cathode of every MITL-circuit element where the electric field has previously exceeded a constant threshold value $E_{\mathrm{th}}$; we assume

$$
E_{\mathrm{th}}=240 \mathrm{kV} / \mathrm{cm} \text {. }
$$

This threshold is that deduced by Di Capua and Pellinen [50]. Once this field is reached in a MITL element, electrons are always emitted thereafter in that element. Version B models a Child-Langmuir loss of electrons in every MITL element where $E_{\text {th }}$ has previously been exceeded, and magnetic insulation is not established. 
TABLE II. Description of the seven versions of the TL transmission-line-circuit model that are used to obtain the results summarized by Table III. All seven versions assume that the $z$-pinch load can be modeled as an infinitely thin and perfectly stable cylindrical foil, and that the pinch-radius convergence ratio is $10: 1$.

\begin{tabular}{|c|c|c|c|c|c|c|c|}
\hline $\begin{array}{l}\text { TL-model } \\
\text { version }\end{array}$ & $\begin{array}{l}\text { Transmission-line } \\
\text { impedances } \\
\text { and lengths }\end{array}$ & $\begin{array}{l}\text { Electron loss } \\
\text { in the MITLs } \\
\text { before insulation } \\
\text { is established }\end{array}$ & $\begin{array}{l}\text { Collisionless } \\
\text { MITL-flow- } \\
\text { electron loss } \\
\text { after insulation } \\
\text { is established }\end{array}$ & $\begin{array}{l}\text { MITL-gap } \\
\text { closure }\end{array}$ & $\begin{array}{l}\text { Energy loss } \\
\text { to electrodes } \\
\text { operated at } \\
\text { high lineal } \\
\text { current densities }\end{array}$ & $\begin{array}{l}\text { Pinch } \\
\text { resistance }\end{array}$ & $\begin{array}{l}\text { Collisional MITL- } \\
\text { flow-electron } \\
\text { loss after } \\
\text { insulation is } \\
\text { established }\end{array}$ \\
\hline A & X & & & & & & \\
\hline B & X & $X$ & & & & & \\
\hline $\mathrm{C}$ & $X$ & $X$ & $X$ & & & & \\
\hline D & X & X & X & $X$ & & & \\
\hline $\mathrm{E}$ & X & X & X & X & $X$ & & \\
\hline $\mathrm{F}$ & $X$ & $X$ & $X$ & $X$ & $X$ & $X$ & \\
\hline $\mathrm{G}$ & $X$ & $X$ & & $X$ & $X$ & $X$ & $X$ \\
\hline
\end{tabular}

TABLE III. Calculated results given by the seven TL-model versions outlined by Table II. The results assume a $z$-pinch load with a 2$\mathrm{cm}$ height, 2-cm initial radius, and 4.27-mg total mass, which was the $Z$ accelerator's baseline load. The effective peak pinch current and effective pinch implosion time are defined in Appendix C.

\begin{tabular}{|c|c|c|c|c|c|c|c|c|c|c|}
\hline $\begin{array}{l}\text { TL-model } \\
\text { version }\end{array}$ & $\begin{array}{c}\text { Peak } \\
\text { electrical } \\
\text { power at } \\
\text { the stack } \\
\text { (TW) }\end{array}$ & $\begin{array}{l}\text { Energy } \\
\text { delivered } \\
\text { to the stack } \\
\text { at pinch } \\
\text { stagnation } \\
\text { (MJ) }\end{array}$ & $\begin{array}{c}\text { Peak } \\
\text { average } \\
\text { stack } \\
\text { voltage } \\
\text { (MV) }\end{array}$ & $\begin{array}{c}\text { Peak total } \\
\text { outer-MITL } \\
\text { current } \\
\text { (MA) }\end{array}$ & $\begin{array}{c}\text { Peak } \\
\text { pinch } \\
\text { current } \\
\text { (MA) }\end{array}$ & $\begin{array}{c}\text { Difference } \\
\text { between the } \\
\text { peak } \\
\text { outer-MITL } \\
\text { and peak pinch } \\
\text { currents (MA) }\end{array}$ & $\begin{array}{c}\text { Pinch } \\
\text { implosion } \\
\text { time (ns) }\end{array}$ & $\begin{array}{l}\text { Nominal } \\
\text { pinch } \\
\text { kinetic } \\
\text { energy at } \\
\text { stagnation } \\
\text { (MJ) }\end{array}$ & $\begin{array}{l}\text { Effective } \\
\text { peak } \\
\text { pinch } \\
\text { current } \\
\text { (MA) }\end{array}$ & $\begin{array}{l}\text { Effective } \\
\text { pinch } \\
\text { implosion } \\
\text { time } \\
(\mathrm{ns}) \\
\end{array}$ \\
\hline A & 54.9 & 3.31 & 3.05 & 19.8 & 19.7 & 0.1 & 104 & 1.33 & 19.2 & 113 \\
\hline B & 55.0 & 3.31 & 3.05 & 19.8 & 19.7 & 0.1 & 102 & 1.33 & 19.2 & 113 \\
\hline C & 55.1 & 3.34 & 3.06 & 20.2 & 19.6 & 0.6 & 108 & 1.31 & 19.1 & 114 \\
\hline D & 55.2 & 3.34 & 3.06 & 20.2 & 19.6 & 0.6 & 108 & 1.31 & 19.0 & 114 \\
\hline E & 55.2 & 3.34 & 3.08 & 20.1 & 19.5 & 0.6 & 108 & 1.28 & 18.9 & 115 \\
\hline F & 55.3 & 3.36 & 3.13 & 19.7 & 19.1 & 0.6 & 109 & 1.22 & 18.4 & 118 \\
\hline G & 54.3 & 3.37 & 3.12 & 20.0 & 19.1 & 0.9 & 107 & 1.19 & 18.2 & 120 \\
\hline
\end{tabular}

The TL code assumes magnetic insulation is not established in a MITL-circuit element when there is no physical solution to the following 1D steady-state pressure-balance equation for a MITL:

$$
V_{a}=Z_{0}\left(I_{a}^{2}-I_{k}^{2}\right)^{1 / 2}-\frac{m c^{2}}{2 e}\left(\frac{I_{a}^{2}}{I_{k}^{2}}-1\right)
$$

This model is developed in Appendix A of Ref. [51], and outlined in Sec. VC of [52]. The quantity $V_{a}$ is the total voltage across the MITL-circuit element, $Z_{0}$ is the MITL element's geometric impedance, $I_{a}$ is the anode current (which is the total current in the MITL element), $I_{k}$ is the cathode current, $m$ is the electron rest mass, $c$ is the speed of light, and $e$ is the absolute value of the electron charge. When the quantities $V_{a}, Z_{0}$, and $I_{a}$ are such that there is no purely real value of $I_{k}$ that solves Eq. (4), TL code assumes the MITL element is not magnetically insulated.

\section{Electron loss after insulation is established, assuming collisionless flow electrons}

The electron current that $\mathbf{E} \times \mathbf{B}$ drifts in a MITL after magnetic insulation is established, i.e., the flow-electron current $I_{f}$, is defined by

$$
I_{f} \equiv I_{a}-I_{k}
$$

Equation (4) assumes the flow electrons are collisionless. Version C uses Eqs. (4) and (5) to calculate the maximum value of $I_{f}$ in each of the four outer MITLs, and makes the simplifying and conservative assumption that the sum of the four maximum values is lost in the vicinity of the double-post-hole convolute. (This assumption is motivated by 3D PIC simulations, which show that electrons launched in the MITLs upstream of a convolute are lost in the vicinity of the convolute [9,35-39].) Consequently, version $\mathrm{C}$ assumes that once electrons are launched in a MITL, they are not retrapped. Version $\mathrm{C}$ also assumes that 
$I_{f} / I_{a} \ll 1$ and the two-way transit time of the MITLs is short compared to the rise time of the current pulse.

\section{Gap closure}

Version D assumes that once $E_{\text {th }}$ is exceeded in a MITLcircuit element, the cathode plasma in that element expands thereafter at a constant rate $v$ toward the anode.

Cathode-plasma-expansion velocities of $1-3 \mathrm{~cm} / \mu \mathrm{s}$ have been reported for $\mathrm{C}, \mathrm{Al}, \mathrm{Cu}, \mathrm{Mo}, \mathrm{Pb}$, and stainlesssteel electrodes, for systems operated at currents as high as $200 \mathrm{kA}$ [53-60]. To determine whether such measurements apply at megampere currents, we conducted MITL-gapclosure experiments on the Saturn accelerator.

We measured the anode current immediately before and after a 2.4-cm-long coaxial MITL that fed a 3-nH coaxial inductive short-circuit load. We tested MITLs with 1- and 2-mm anode-cathode gaps with approximately uniform electric fields. We successfully operated the 2-mm-gap MITL at $0.8 \mathrm{MV}(4 \mathrm{MV} / \mathrm{cm}), 9 \mathrm{MA}(0.7 \mathrm{MA} / \mathrm{cm})$, and $1.5 \mathrm{TW} / \mathrm{cm}^{2}$, and demonstrated $100 \%$ current-transport efficiency over a $\sim 70$-ns power pulse. (Because the load was an inductive short circuit, peak voltage occurred at 4.5 MA; the voltage was essentially zero at peak current. Successful operation was achieved only when Saturn's prepulse switches were open. When the switches were closed, Saturn's voltage prepulse caused the 2-mm gap to close during the pulse.) The 1-mm-gap MITL did not successfully transport current. We infer from these measurements that the average cathode-plasma-expansion velocity was less than $3 \mathrm{~cm} / \mu \mathrm{s}$, which is consistent with the velocities reported in Refs. [53-60]. We assume in TL that

$$
v=2.5 \mathrm{~cm} / \mu \mathrm{s} .
$$

To calculate the Child-Langmuir electron loss in a MITL-circuit element before magnetic insulation is established, TL-model version D assumes the MITL's anodecathode gap $g(t)$ is given by

$$
g(t)=g_{0}-v t,
$$

where $t$ is the time since the threshold electric field $E_{\text {th }}$ was reached and $g_{0}$ is the initial gap. To calculate the flowelectron current in an outer-MITL circuit element, version D uses [instead of Eq. (4)] the following expression [9]

$$
V_{a}=Z_{0}\left[1-\left(v t / g_{0}\right)\right]\left(I_{a}^{2}-I_{k}^{2}\right)^{1 / 2}-\frac{m c^{2}}{2 e}\left(\frac{I_{a}^{2}}{I_{k}^{2}}-1\right) .
$$

The flow-electron currents launched in the double-posthole convolute and inner MITL are small and are neglected.

For typical MITL-cathode-plasma temperatures and densities, the skin depth of the cathode plasma is on the order of, or is greater than, its thickness [57,58]. Hence, we make the simplifying assumption that the expansion of the cathode plasma affects only the MITL-electron-flow cur- rent according to Eq. (8), and does not change the inductance of any of the MITL-circuit elements. Cathodeplasma expansion changes the capacitance, but for the MITLs considered herein the inductive energy of a MITL is much greater than its capacitive energy, so MITLcapacitance changes are also neglected. Neglecting both inductance and capacitance changes leads to the use of $Z_{0}$, unaltered, for all circuit calculations except for those of the Child-Langmuir loss before insulation is established, and outer-MITL flow-current loss afterward.

2D PIC simulations of the $Z$-stack-MITL system suggest that the electron dose to the outer-MITL anodes never exceeded $50 \mathrm{~J} / \mathrm{g}$ [9]. Since at least $\sim 150 \mathrm{~J} / \mathrm{g}$ is needed to form an anode plasma on the surface of a stainless-steel electrode [61-65], the TL model neglects anode-plasma effects in the outer MITLs.

Initial 3D PIC simulations of the $Z$ double-post-hole convolute and inner MITL indicated that anode plasmas were formed in these regions, but space-charge-limited ion emission from such anode areas could be neglected [3539]. References [35-39] also suggested that the intrinsic efficiency of the $Z$ convolute was high, due to the large anode-cathode gaps and small areas of the convolute elements. Motivated by these results, the TL model assumes that the intrinsic efficiency of the $Z$ convolute was $100 \%$, and that the only loss that occurred in the vicinity of the convolute was due to outer-MITL flow electrons that were launched upstream, as discussed in Sec. III C.

However, the simulations described in Refs. [35-39] did not model the expansion of anode and cathode plasmas. Recent 3D PIC simulations demonstrate that cathodeplasma expansion could have a significant effect on convolute performance [41-43]. Such simulations are part of an ongoing effort to develop more realistic circuit models of the double-post-hole convolute and inner MITL for future inclusion in TL and other circuit codes.

\section{E. Energy lost to conductors operated at high lineal current densities}

At sufficiently high lineal current densities, the energy lost to a MITL electrode due to Ohmic heating, magnetic diffusion, $\mathbf{j} \times \mathbf{B}$ work, and the increase in inductance due to motion of the vacuum-electrode boundary can be significant [66]. Version E models such energy loss to the electrodes of the inner MITL, which are located inside a 6$\mathrm{cm}$ radius. The loss is estimated using Eq. (35) of Ref. [66]. Version E neglects the energy that is lost to electrodes elsewhere in the MITL system, since such losses are small and can be neglected.

\section{F. Pinch resistance}

Version $\mathrm{F}$ includes a constant pinch resistance per unit pinch length $R_{p}$, and makes the simplifying assumption that 


$$
R_{p}=5 \mathrm{~m} \Omega / \mathrm{cm},
$$

as estimated by the plasma-resistivity model developed in Ref. [67].

\section{G. Electron loss after magnetic insulation is established, assuming collisional flow electrons}

Equations (4) and (8) assume that after magnetic insulation is established, the electron flow in a MITL is collisionless. Reference [52] develops instead a MITL model that assumes the flow is collisional. Table II of [52] suggests that, when MITL anode-cathode gaps are on the order of a few centimeters or less, the collisional model is in better agreement with experiment. Motivated by this observation, version $\mathrm{G}$ makes the simplifying and conservative assumption that the electron flow is fully collisional, and that the flow current can be calculated using [instead of Eq. (8)] the following expression:

$$
V_{a}=\frac{2}{3} Z_{0}\left[1-\left(v t / g_{0}\right)\right]\left(I_{a}^{2}-I_{k}^{2}\right)^{1 / 2} .
$$

\section{H. Effects of the various assumptions}

Table III illustrates the effects of the various assumptions outlined above. As suggested by the table, TL-model versions $A-G$ give comparable values for most of the electrical quantities considered. For example, the effective peak pinch currents for all the versions are the same to within 5\%. This is because the performance of the $Z$ accelerator's stack-MITL system was determined primarily by the initial system inductance and time-dependent inductance of the imploding z-pinch load. However, the versions give significantly different values for the difference between the peak outer-MITL and peak load currents.

\section{Voltage used to drive the TL simulations}

As suggested by Fig. 4, each of the TL simulations described in this article are driven by an open-circuit voltage $V_{\mathrm{oc}}$. The voltage that is used to drive a simulation is constructed from measured stack voltages, measured stack currents, and calculated inductances between the locations of the measurements and the output ends of the water-insulated bi-plate transmission lines. The constructed open-circuit voltages obtained for $Z$ shots 51, $52,540,541,619,685$, and 783 are averaged to obtain the open-circuit voltage that is used to drive all the TL simulations (described herein) of this set of shots. Opencircuit voltages used for TL simulations of the other shots discussed in this article are similarly constructed.

Figure 5 plots the forward-going voltage (which is exactly one-half of the open-circuit voltage) that is obtained for shots 51, 52, 540, 541, 619, 685, and 783. (The forwardgoing voltage is that which propagated in the 36 waterinsulated bi-plate transmission lines toward the stackMITL system.) Figure 5 also plots the average, over all these shots, of the average value of the insulator-stack

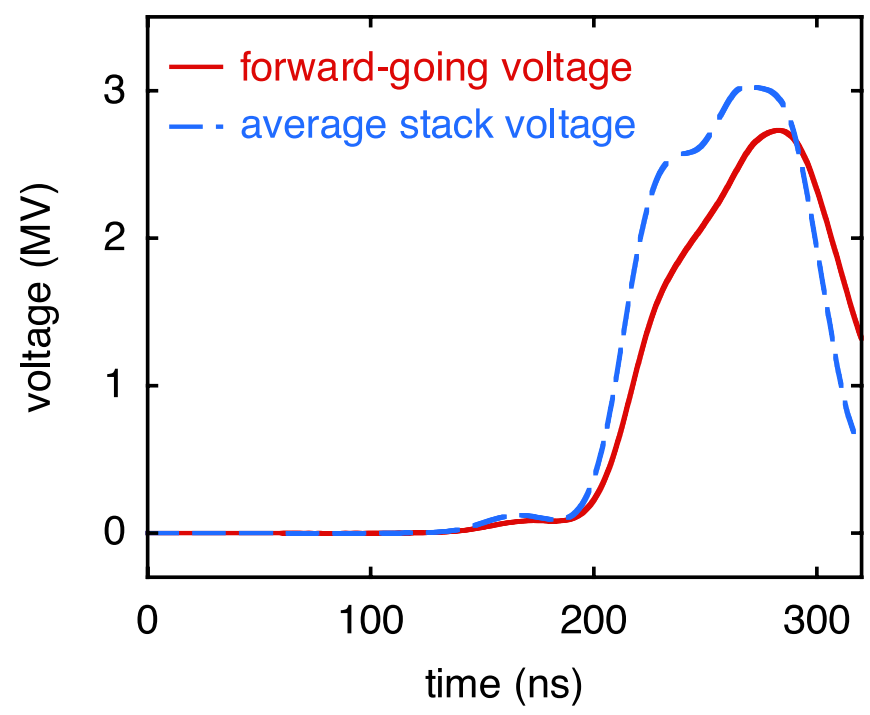

FIG. 5. (Color) Comparison of the average insulator-stack voltage with the forward-going voltage for the seven shots taken with Z's baseline load. If the impedance of each of the four stack-MITL levels were constant and equal to $Z_{b}$ (as defined by Fig. 4), the stack voltage would be identical to the forward-going voltage. The above plot indicates the extent to which the stack voltage is modified by the actual time-dependent impedances of the four stack-MITL levels.

voltages measured on levels A, B, C, and D. If the impedance of each of the four stack-MITL levels were constant and identical to $Z_{b}$ (defined by Fig. 4), then the forwardgoing voltage would be identical to the average stack voltage. Figure 5 indicates the extent to which the stack voltage is modified by the actual time-dependent impedances of the four stack-MITL levels.

The peak value of the total forward-going power in the 36 water-insulated transmission lines was $62 \mathrm{TW}$. The peak power at the stack was $\sim 55 \mathrm{TW}$, which is less than $62 \mathrm{TW}$ because the stack-MITL system was not perfectly impedance matched to the 36 water lines.

\section{OPTIMIZED OUTER-MITL-SYSTEM IMPEDANCE}

Each of the seven TL-model versions described in Sec. III makes a different set of assumptions about various MITL-energy-loss mechanisms. However, all versions assume the same set of transmission-line impedances and electrical lengths for the 300 stack-MITL-system circuit elements. In this section, we estimate effects due to changes in the impedance profiles of the four outer MITLs, for two different $z$-pinch loads.

We consider three different outer-MITL designs, labeled here as I, II, and III. These are the three designs that were considered, and computationally evaluated, during the $Z$-accelerator design effort [2,9]. Design II is the baseline design; i.e., the design that was selected and subsequently used on all $1700 \mathrm{Z}$-accelerator shots. 
TABLE IV. Nominal geometric impedances of the three outer-MITL-system designs considered in this article. (We define the geometric impedance to be the impedance in the absence of electron emission, electron flow, and gap closure.)

\begin{tabular}{|c|c|c|c|c|c|}
\hline $\begin{array}{l}\text { Outer-MITL- } \\
\text { system } \\
\text { design }\end{array}$ & $\begin{array}{c}\text { Level-A } \\
\text { MITL } \\
\text { impedance } \\
\text { at a } 1-\mathrm{m} \text { radius }(\Omega)\end{array}$ & $\begin{array}{c}\text { Level-B } \\
\text { MITL } \\
\text { impedance } \\
\text { at a } 1-\mathrm{m} \text { radius }(\Omega)\end{array}$ & $\begin{array}{c}\text { Level-C } \\
\text { MITL } \\
\text { impedance } \\
\text { at a } 1-\mathrm{m} \text { radius }(\Omega)\end{array}$ & $\begin{array}{c}\text { Level-D } \\
\text { MITL } \\
\text { impedance } \\
\text { at a } 1-\mathrm{m} \text { radius }(\Omega)\end{array}$ & $\begin{array}{c}\text { Outer-MITL- } \\
\text { system } \\
\text { impedance } \\
\text { at a } 1 \text {-m radius }(\Omega)\end{array}$ \\
\hline I & 2.65 & 2.70 & 3.79 & 3.82 & 0.785 \\
\hline II & 1.98 & 2.02 & 2.74 & 2.73 & 0.578 \\
\hline III & 1.42 & 1.49 & 1.82 & 1.81 & 0.404 \\
\hline
\end{tabular}

The nominal geometric impedances of the outer MITLs for the three designs are listed in Table IV. These are the impedances at a radius of $1 \mathrm{~m}$. Design I has outer-MITL impedances that are a factor of 1.4 higher than those of design II; design III has impedances that are a factor of 1.4 lower. (Designs I, II, and III are identical to the 5-3.5-5, 107-10, and 20-14-20 designs described in Refs. [2,9].)

The calculated performances of the three designs are summarized by Tables V and VI. As suggested by these tables, the three designs deliver comparable energies to the load. This is due to offsetting effects: Although decreasing the geometric outer-MITL-system impedance decreases the inductance, and hence increases the outer-MITL anode current, it also increases the MITL-flow current, which is subsequently lost. As a result, for the conditions considered by Tables V and VI, the energy delivered to the load is constant to within $4 \%$.

However, the three designs give significantly different values for the nominal flow-electron loss, which we define to be the difference between the peak MITL and peak load currents. Tables V and VI suggest designs I and II are superior to III, since I and II deliver comparable energies to the load, with much less flow-electron loss than III. Less electron loss means less damage to MITL hardware, and

TABLE V. Results of TL simulations for MITL designs I, II, and III. Nominal geometric impedances of the four outer MITLs for each design are listed in Table IV. The simulations assume a $z$-pinch load with a 2-cm length, 2-cm initial radius, and 4.27-mg total mass, which was the $Z$ accelerator's baseline load. The effective peak pinch current and effective pinch implosion time are defined in Appendix C.

\begin{tabular}{|c|c|c|c|c|c|c|c|c|c|c|}
\hline $\begin{array}{l}\text { Outer-MITL- } \\
\text { system } \\
\text { design }\end{array}$ & $\begin{array}{l}\text { Peak } \\
\text { electrical } \\
\text { power at } \\
\text { the stack } \\
(\mathrm{TW})\end{array}$ & $\begin{array}{l}\text { Energy } \\
\text { delivered } \\
\text { to the } \\
\text { stack at } \\
\text { pinch } \\
\text { stagnation } \\
\text { (MJ) }\end{array}$ & $\begin{array}{c}\text { Peak } \\
\text { average } \\
\text { stack } \\
\text { voltage } \\
\text { (MV) }\end{array}$ & $\begin{array}{c}\text { Peak } \\
\text { total } \\
\text { outer-MITL } \\
\text { current } \\
\text { (MA) }\end{array}$ & $\begin{array}{l}\text { Peak } \\
\text { pinch } \\
\text { current } \\
\text { (MA) }\end{array}$ & $\begin{array}{l}\text { Difference } \\
\text { between } \\
\text { the peak } \\
\text { outer-MITL } \\
\text { and peak } \\
\text { pinch currents } \\
\text { (MA) }\end{array}$ & $\begin{array}{l}\text { Pinch } \\
\text { implosion } \\
\text { time } \\
(\mathrm{ns})\end{array}$ & $\begin{array}{l}\text { Nominal } \\
\text { pinch } \\
\text { kinetic } \\
\text { energy at } \\
\text { stagnation } \\
(\mathrm{MJ})\end{array}$ & $\begin{array}{c}\text { Effective } \\
\text { peak } \\
\text { pinch } \\
\text { current } \\
\text { (MA) }\end{array}$ & $\begin{array}{l}\text { Effective } \\
\text { pinch } \\
\text { implosion } \\
\text { time } \\
\text { (ns) }\end{array}$ \\
\hline I & 53.5 & 3.32 & 3.23 & 19.3 & 18.8 & 0.5 & 106 & 1.17 & 18.0 & 120 \\
\hline II & 54.3 & 3.37 & 3.12 & 20.0 & 19.1 & 0.9 & 107 & 1.19 & 18.2 & 120 \\
\hline III & 54.3 & 3.45 & 2.96 & 21.1 & 19.3 & 1.8 & 107 & 1.19 & 18.2 & 120 \\
\hline
\end{tabular}

TABLE VI. Results of TL simulations for MITL designs I, II, and III. Nominal geometric impedances of the four outer MITLs for each design are listed in Table IV. These simulations assume a $z$-pinch load with a 1-cm length, 1-cm initial radius, and 5.88-mg total mass. The effective peak pinch current and effective pinch-implosion time are defined in Appendix C.

\begin{tabular}{|c|c|c|c|c|c|c|c|c|c|c|}
\hline $\begin{array}{l}\text { Outer-MITL- } \\
\text { system } \\
\text { design } \\
\end{array}$ & $\begin{array}{c}\text { Peak } \\
\text { electrical } \\
\text { power at } \\
\text { the stack } \\
(\mathrm{TW})\end{array}$ & $\begin{array}{l}\text { Energy } \\
\text { delivered } \\
\text { to the } \\
\text { stack at } \\
\text { pinch } \\
\text { stagnation } \\
\text { (MJ) }\end{array}$ & $\begin{array}{c}\text { Peak } \\
\text { average } \\
\text { stack } \\
\text { voltage } \\
(\mathrm{MV}) \\
\end{array}$ & $\begin{array}{c}\text { Peak } \\
\text { total } \\
\text { outer-MITL } \\
\text { current } \\
\text { (MA) }\end{array}$ & $\begin{array}{l}\text { Peak } \\
\text { pinch } \\
\text { current } \\
\text { (MA) }\end{array}$ & $\begin{array}{c}\text { Difference } \\
\text { between } \\
\text { the peak } \\
\text { outer-MITL } \\
\text { and peak } \\
\text { pinch currents } \\
\text { (MA) }\end{array}$ & $\begin{array}{l}\text { Pinch } \\
\text { implosion } \\
\text { time } \\
\text { (ns) }\end{array}$ & $\begin{array}{l}\text { Nominal } \\
\text { pinch } \\
\text { kinetic } \\
\text { energy at } \\
\text { stagnation } \\
(\mathrm{MJ})\end{array}$ & $\begin{array}{l}\text { Effective } \\
\text { peak } \\
\text { pinch } \\
\text { current } \\
\text { (MA) }\end{array}$ & $\begin{array}{l}\text { Effective } \\
\text { pinch } \\
\text { implosion } \\
\text { time } \\
(\mathrm{ns}) \\
\end{array}$ \\
\hline I & 57.8 & 3.23 & 3.32 & 19.7 & 19.0 & 0.7 & 93 & 0.70 & 19.7 & 92 \\
\hline II & 57.8 & 3.30 & 3.23 & 20.3 & 19.4 & 0.9 & 96 & 0.72 & 20.0 & 90 \\
\hline III & 57.8 & 3.41 & 3.07 & 21.5 & 19.7 & 1.8 & 91 & 0.73 & 20.1 & 90 \\
\hline
\end{tabular}


less thick-target bremsstrahlung that could interfere with diagnostics.

Design II was selected over I as the baseline for $Z$, since II delivers slightly more current and energy to the load, and the nominal flow-electron loss of II was considered to be acceptable for $Z$ experiments [2,9]. However, for the load assumed by Table $\mathrm{V}$, design I delivers only $1 \%$ less current and $2 \%$ less energy to the load; for the load assumed by Table VI, design I delivers only $2 \%$ less current and $3 \%$ less energy. It is clear that design I would have performed essentially as well as II, with substantially less flowelectron loss.

As suggested by Table IV, the nominal geometric outerMITL impedance of MITL-design II is $0.578 \Omega$. The TL simulations (performed with TL-version G and MITLdesign II) discussed in Sec. III suggest that, at the time of peak pinch current, the effective impedance of the convolute-load system (the voltage-current ratio within the convolute) was $0.123 \Omega$. At pinch stagnation, the im- pedance was $0.435 \Omega$. Therefore the nominal geometric impedance of an optimized outer-MITL system is a factor of $3.0 \pm 1.7$ greater than the effective impedance of the convolute-load system. This result is consistent with the prediction of the analytic MITL model developed in Appendix B. Under the conditions assumed by the model-which neglects gap closure-the electromagnetic power delivered by a MITL to a constant-impedance load is maximized when the ratio of the MITL's geometric impedance to that of the load is $\sim 2$. It is clear that the presence of gap closure increases the optimum ratio.

\section{COMPARISON OF TL-MODEL CALCULATIONS WITH MEASUREMENTS}

In this section we compare calculations of the TL model of the $Z$ accelerator's stack-MITL system with measurements that were performed on three sets of $Z$ experiments. All the calculations presented herein assume MITL-design

TABLE VII. Comparison of TL-model calculations with measurements taken on the $Z$ accelerator. (The calculations listed here are a subset of those given for MITL-design II in Table V.) The measurements are average values of data acquired on seven nominally identical $Z$ shots. The load was a $z$ pinch with a $2-\mathrm{cm}$ length, $2-\mathrm{cm}$ initial radius, and 4.27-mg total mass, which was the $Z$ accelerator's baseline load. The Marx-charge voltage on these shots was $90 \mathrm{kV}$.

\begin{tabular}{lcccccc}
\hline \hline & $\begin{array}{c}\text { Energy } \\
\text { Peak } \\
\text { electrical } \\
\text { power } \\
\text { at the }\end{array}$ & $\begin{array}{c}\text { delivered } \\
\text { to the } \\
\text { stack at } \\
\text { pinch }\end{array}$ & $\begin{array}{c}\text { Peak } \\
\text { average } \\
\text { stack }\end{array}$ & $\begin{array}{c}\text { Peak } \\
\text { total } \\
\text { outer-MITL }\end{array}$ & $\begin{array}{c}\text { Peak } \\
\text { pinch }\end{array}$ & $\begin{array}{c}\text { Pimplosion } \\
\text { implon }\end{array}$ \\
& stack & stagnation & voltage & current & current & time \\
& $(\mathrm{TW})$ & $(\mathrm{MJ})$ & $(\mathrm{MV})$ & $(\mathrm{MA})$ & $(\mathrm{MA})$ & (ns) \\
\hline Calculation & 54.3 & 3.37 & 3.12 & 20.0 & 19.1 & 107 \\
Measurement & 55.1 & 3.31 & 3.06 & 20.3 & 19.0 & 106 \\
Difference & $-1.5 \%$ & $1.8 \%$ & $2.0 \%$ & $-1.5 \%$ & $0.5 \%$ & $0.9 \%$ \\
Measurement uncertainty & $\pm 7 \%$ & $\pm 7 \%$ & $\pm 5 \%$ & $\pm 5 \%$ & $\pm 5 \%$ & $\pm 4 \%$ \\
\hline \hline
\end{tabular}

TABLE VIII. Comparison of TL-model calculations with measurements taken on the $Z$ accelerator. (The calculations listed here are a subset of those given for MITL-design II in Table VI.) The measurements are average values of data acquired on four nominally identical $Z$ shots. The load was a $z$ pinch with a $1-\mathrm{cm}$ length, $1-\mathrm{cm}$ initial radius, and 5.88-mg total mass. The Marx-charge voltage on these shots was $90 \mathrm{kV}$.

\begin{tabular}{|c|c|c|c|c|c|c|}
\hline & $\begin{array}{c}\text { Peak } \\
\text { electrical } \\
\text { power } \\
\text { at the } \\
\text { stack } \\
(\mathrm{TW})\end{array}$ & $\begin{array}{l}\text { Energy } \\
\text { delivered } \\
\text { to the } \\
\text { stack at } \\
\text { pinch } \\
\text { stagnation } \\
(\mathrm{MJ})\end{array}$ & $\begin{array}{c}\text { Peak } \\
\text { average } \\
\text { stack } \\
\text { voltage } \\
(\mathrm{MV})\end{array}$ & $\begin{array}{c}\text { Peak } \\
\text { total } \\
\text { outer-MITL } \\
\text { current } \\
\text { (MA) }\end{array}$ & $\begin{array}{c}\text { Peak } \\
\text { pinch } \\
\text { current } \\
\text { (MA) }\end{array}$ & $\begin{array}{l}\text { Pinch } \\
\text { implosion } \\
\text { time } \\
\text { (ns) }\end{array}$ \\
\hline Calculation & 57.8 & 3.30 & 3.23 & 20.3 & 19.4 & 96 \\
\hline Measurement & 58.0 & 3.27 & 3.14 & 20.8 & 18.5 & 95 \\
\hline Difference & $-0.3 \%$ & $0.9 \%$ & $2.9 \%$ & $-2.4 \%$ & $4.9 \%$ & $1.1 \%$ \\
\hline Measurement uncertainty & $\pm 7 \%$ & $\pm 7 \%$ & $\pm 5 \%$ & $\pm 5 \%$ & $\pm 5 \%$ & $\pm 4 \%$ \\
\hline
\end{tabular}


TABLE IX. Comparison of TL-model calculations with measurements taken on the $Z$ accelerator. The measurements are average values of data acquired on two nominally identical $Z$ shots. The load was a $z$ pinch with a $1-\mathrm{cm}$ length, $1-\mathrm{cm}$ initial radius, and 2.74-mg total mass. The Marx-charge voltage on these shots was $60 \mathrm{kV}$.

\begin{tabular}{|c|c|c|c|c|c|c|}
\hline & $\begin{array}{c}\text { Peak } \\
\text { electrical } \\
\text { power } \\
\text { at the } \\
\text { stack } \\
\text { (TW) }\end{array}$ & $\begin{array}{l}\text { Energy } \\
\text { delivered } \\
\text { to the } \\
\text { stack at } \\
\text { pinch } \\
\text { stagnation } \\
\text { (MJ) }\end{array}$ & $\begin{array}{c}\text { Peak } \\
\text { average } \\
\text { stack } \\
\text { voltage } \\
\text { (MV) }\end{array}$ & $\begin{array}{c}\text { Peak } \\
\text { total } \\
\text { outer-MITL } \\
\text { current } \\
\text { (MA) }\end{array}$ & $\begin{array}{l}\text { Peak } \\
\text { pinch } \\
\text { current } \\
\text { (MA) }\end{array}$ & $\begin{array}{l}\text { Pinch } \\
\text { implosion } \\
\text { time } \\
\text { (ns) }\end{array}$ \\
\hline Calculation & 25.7 & 1.44 & 2.15 & 13.5 & 12.9 & 97 \\
\hline Measurement & 24.6 & 1.42 & 2.13 & 13.0 & 12.8 & 94 \\
\hline Difference & $4.5 \%$ & $1.4 \%$ & $0.9 \%$ & $3.8 \%$ & $0.8 \%$ & $3.2 \%$ \\
\hline Measurement uncertainty & $\pm 7 \%$ & $\pm 7 \%$ & $\pm 5 \%$ & $\pm 5 \%$ & $\pm 5 \%$ & $\pm 4 \%$ \\
\hline
\end{tabular}

II, which (as discussed above) was the design used on all of the shots taken on $Z$. The calculations discussed in this section assume TL-model version $\mathrm{G}$ (which is described in Table II). The comparison of calculations with measurements is summarized by Tables VII, VIII, and IX and Figs. 6-10.

The measurements listed in Table VII are average values of data acquired on seven nominally identical $Z$-accelerator shots, which are numbered 51, 52, 540, $541,619,685$, and 783 . On these shots the load was a $z$ pinch with a $2-\mathrm{cm}$ length, $2-\mathrm{cm}$ initial radius, and $4.27-\mathrm{mg}$ total mass, which was Z's baseline load. The Marx-charge voltage on these shots was $90 \mathrm{kV}$. The time histories plotted by Figs. 6-10 are averages of measurements performed on the same shots represented by Table VII.

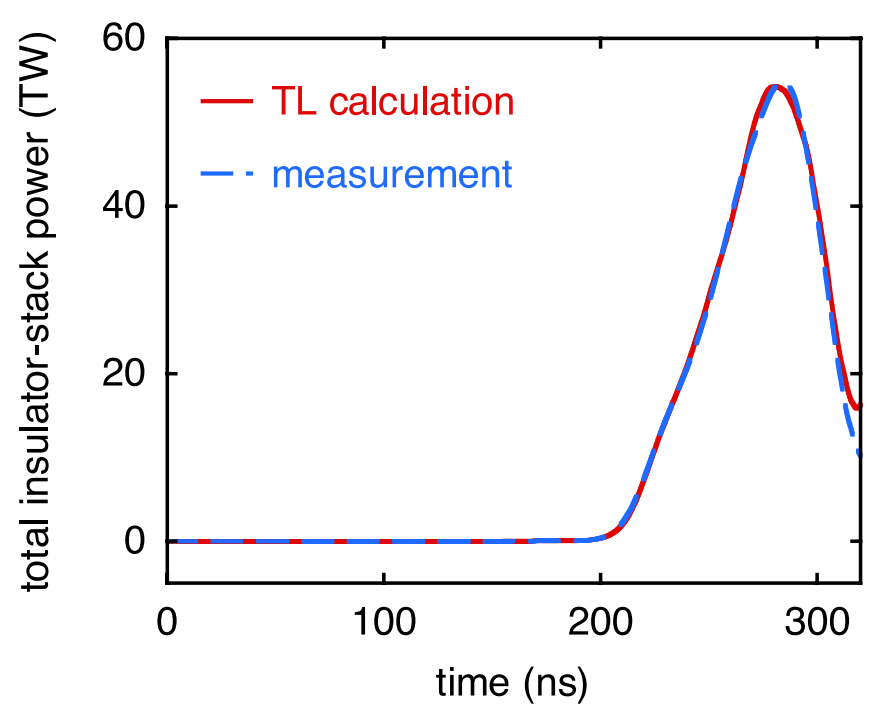

FIG. 6. (Color) Comparison of the TL-calculated total electromagnetic power at the insulator stack, with the average measured total stack power, for the seven shots taken with Z's baseline load. (The average is computed by summing, for each shot, the power over each of the four levels, then taking an average over the shots.)
The measurements listed in Table VIII are average values of data acquired on four nominally identical $Z$-accelerator shots [68], which are numbered 723, 724, 817 , and 818. On these shots the load was a $z$ pinch with a $1-\mathrm{cm}$ length, $1-\mathrm{cm}$ initial radius, and 5.88-mg total mass. The Marx-charge voltage on these shots was $90 \mathrm{kV}$.

The measurements listed in Table IX are average values of data acquired on two nominally identical $Z$-accelerator shots [68], which are numbered 725 and 819. On these shots the load was a $z$ pinch with a $1-\mathrm{cm}$ length, $1-\mathrm{cm}$ initial radius, and 2.74-mg total mass. The Marx charge on these shots was $60 \mathrm{kV}$.

For all three sets of experiments, the simulation results and data presented in Tables VII, VIII, and IX agree to

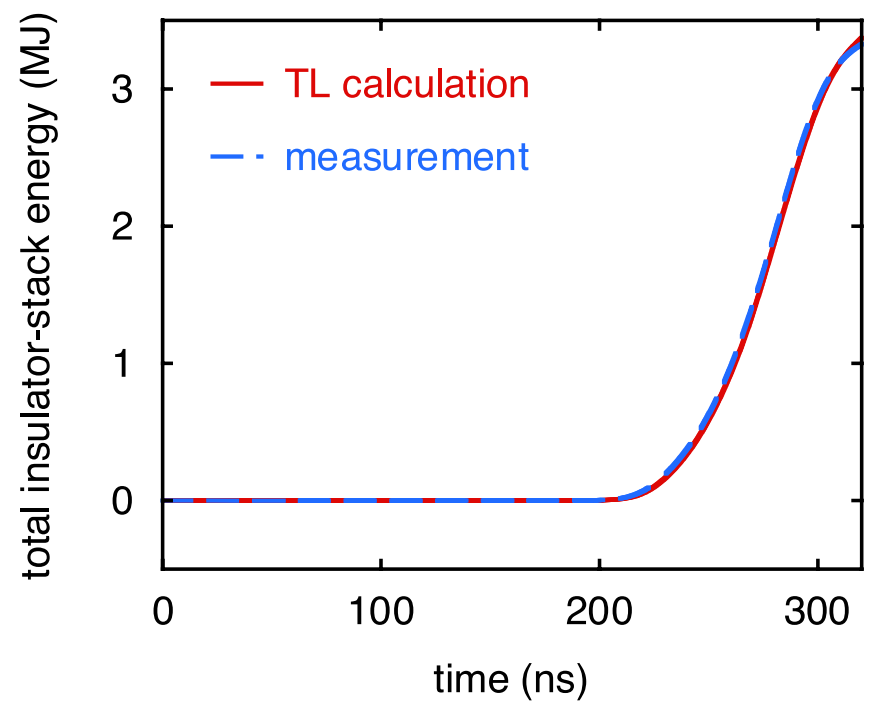

FIG. 7. (Color) Comparison of the TL-calculated total electromagnetic energy at the insulator stack, with the average measured total stack energy, for the seven shots taken with Z's baseline load. (The average is computed by summing, for each shot, the energy over each of the four levels, then taking an average over the shots.) 
within 5\%. We estimate that the total (i.e., combined systematic and random) two-sigma uncertainties in the measurements are as given in the tables [49]. Consequently, as suggested by the tables, the simulation results agree (to within the experimental uncertainties) with the data.

As discussed in Sec. III I, measured stack voltages, measured stack currents, and calculated inductances are used to construct the open-circuit voltage that is used to drive each TL simulation. The open-circuit voltage, together with the 300-circuit-element model of the stackMITL system, are subsequently used to obtain the TL calculations listed in Tables VII, VIII, and IX and plotted by Figs. 6-10.

We caution that given how an open-circuit voltage is constructed, the TL-calculated stack power, stack energy, and stack voltage are not entirely independent of the corresponding measurements. However, the calculated power, energy, and voltage depend not only on the opencircuit voltage, but also on the 300 -element transmissionline-circuit model of the stack-MITL system.

For example, as indicated by Fig. 5, the average stack voltage differs considerably from the forward-going voltage (which is exactly one-half the open-circuit voltage). This is because the stack voltage depends not only on the forward-going voltage, but also on the design of the stackMITL system. [As discussed in Sec. III I, if the impedance of each level of the system were constant and identical to the impedance $Z_{b}$ (defined by Fig. 4), the average stack voltage would be identical to the forward-going voltage. Clearly this is not the case.] Therefore it is of interest to

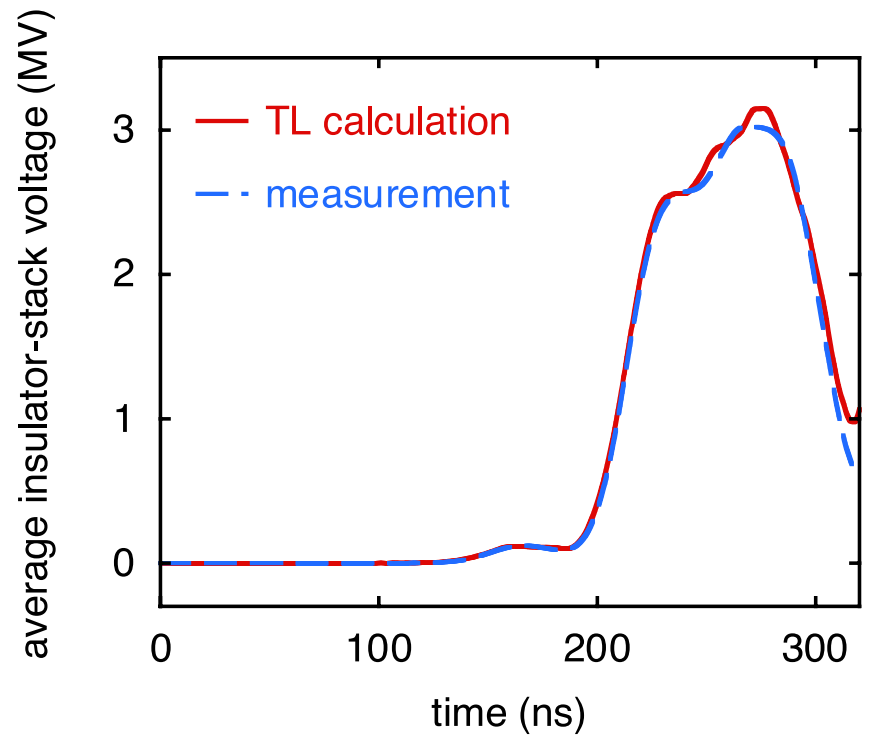

FIG. 8. (Color) Comparison of the TL-calculated average voltage at the insulator stack, with the average measured stack voltage, for the seven shots taken with Z's baseline load. (The average is computed by averaging, for each shot, the voltage over the four levels, then taking an average over the shots.)

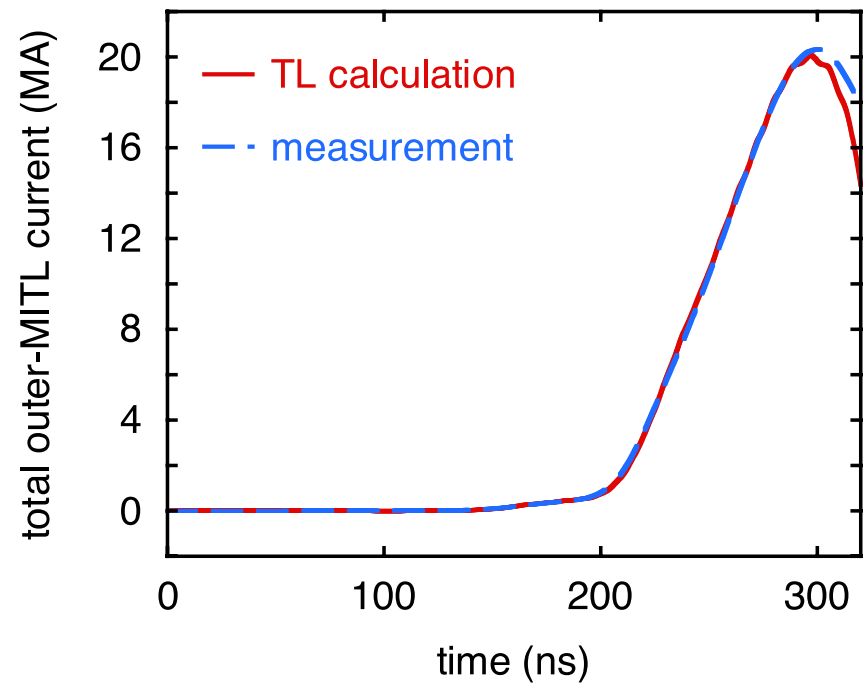

FIG. 9. (Color) Comparison of the TL-calculated total outerMITL current, with the average measured total outer-MITL current, for the seven shots taken with Z's baseline load. (The average is computed by summing, for each shot, the outer-MITL current over each of the four levels for each shot, then taking an average over the shots.)

compare TL calculations of the stack power, energy, and voltage with the corresponding measurements, even though the calculations are not entirely independent of the measurements. The reasonable agreement indicated by Tables VII, VIII, and IX and Figs. 6-8 demonstrates that the 300-element TL model is consistent with the data.

We also observe that the outer-MITL-current, loadcurrent, and implosion-time calculations given in

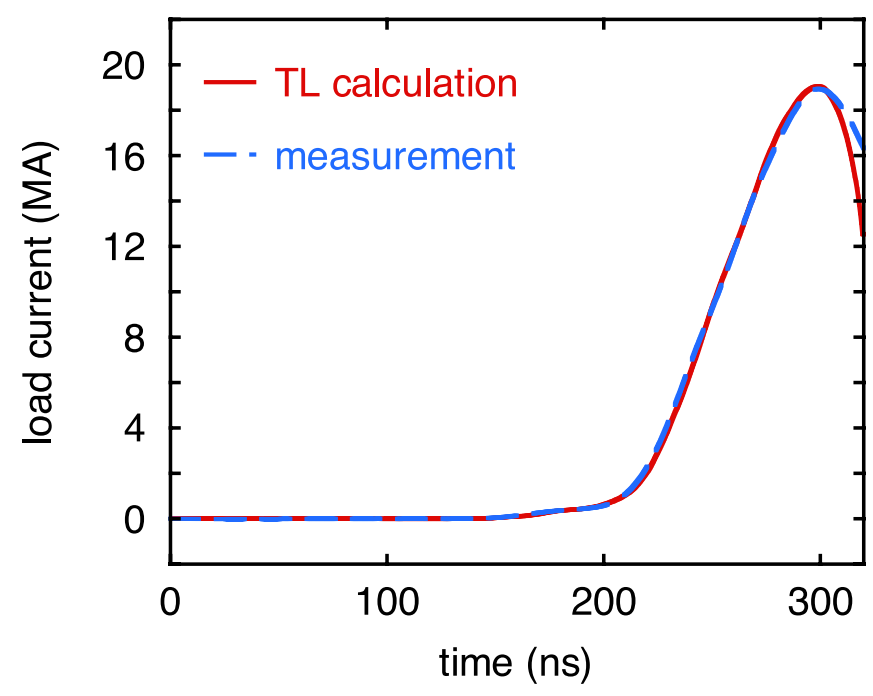

FIG. 10. (Color) Comparison of the TL-calculated $z$-pinch-load current, with the average measured load current, for the seven shots taken with Z's baseline load. (The average is taken over the shots. We assume that the measured load current is given by the inner-MITL current monitors, which were located $6 \mathrm{~cm}$ from the axis of the pinch.) 
Tables VII, VIII, and IX, Fig. 9, and Fig. 10 are independent of the corresponding measurements. The outer-MITLcurrent, load-current, and implosion-time calculations listed in Tables VII, VIII, and IX agree with the measurements to within $5 \%$.

Tables VII, VIII, and IX do not compare the calculated difference between the peak outer-MITL and peak load currents with a measured difference, since we did not have (nor yet have presently) a direct measurement of the flow current that is lost in a MITL system. At this time, the only method we have of estimating this current loss consists of subtracting the load current from the outer-MITL current; i.e., subtracting two quantities with similar magnitudes. The experimental uncertainty in the difference is comparable to the difference itself. Accordingly, all we can say is that, for the cases considered by Tables VII, VIII, and IX, the calculated and measured peak-current differences agree to within experimental uncertainties, but that the uncertainties are large.

Tables VII, VIII, and IX demonstrate reasonable agreement between the TL-calculated values of the peak stack voltage, outer-MITL current, and load current, and the corresponding measurements. However, after peak current, simulations and measurements diverge, as indicated by Figs. 8-10. After peak current, the measured stack voltage is less than that calculated; the measured outer-MITL and load currents are greater.

These discrepancies suggests that, late in time, the load impedance is less than that calculated by the TL model. A lower impedance might be caused by inner-MITL gapclosure effects not included in the TL model [2]. A lower impedance might also be caused by 2D and 3D pinch effects that are not accounted for by TL code's idealized 0D pinch model. 2D and 3D effects cause a pinch implosion to be more diffuse, and result in a time-dependent pinch inductance that, late in time, is less than that calculated using a $0 \mathrm{D}$ approximation. $0 \mathrm{D}$ and $2 \mathrm{D}$ pinch inductances are compared by Fig. 14 of Ref. [69], which suggests that the TL simulations would be improved by a more realistic model of a $z$-pinch load.

\section{DISCUSSION AND SUGGESTIONS FOR FUTURE WORK}

The results presented in this article suggest that the $Z$ accelerator's stack-MITL system performed reasonably well. The system also performed as simulated until peak current. Consequently, it appears that the design of the system, and the TL circuit model described herein, can serve as starting points for the design of stack-MITL systems of future superpower accelerators.

Of course, the TL model cannot replace a fully electromagnetic 3D PIC model-one that simulates all flowelectron, electrode-plasma, and nonideal effects of interest. In addition, the conservative assumptions made by the TL model likely mask a larger number of effects that are not being simulated. However, the agreement indicated by Tables VII, VIII, and IX and Figs. 6-10 suggest that the TL model can provide useful first-order estimates of stackMITL-system performance parameters.

It is clear that the TL model can be significantly improved. For example, as discussed in Sec. III D, TL makes the simplifying assumption that the intrinsic efficiency of the double-post-hole convolute is $100 \%$. Tables VII, VIII, and IX and Figs. 6-10 suggest that, for the $Z$ accelerator, this may be a reasonable assumption; however, it is likely that errors introduced by assuming a $100 \%$ efficiency are masked by other assumptions that are conservative. It would be of interest to develop a more realistic circuit model of the convolute. As discussed in Sec. III D, the simulations described in Refs. [41-43] are part of an ongoing effort to develop such a model.

TL also assumes an idealized 0D pinch model. For the reasons discussed in the last paragraph of Sec. V, it would be of interest to couple TL to a 2D or 3D magnetohydrodynamic (MHD) or PIC model of a $z$-pinch load [69-74], which would calculate more accurately the time-dependent pinch inductance. Present MHD and PIC codes use a highly idealized accelerator-circuit model to drive a pinch implosion; in principle, it is possible to replace such a model with a more complete TL model.

Finally, the TL model can be extended to include an entire accelerator, and not just the accelerator's stackMITL system. This is being demonstrated by Corcoran and colleagues [75], who are developing a TL model of the refurbished $Z$ accelerator (also referred to as $Z R$ ) [43,75-85], which is the successor to $Z$. The TL model of ZR will include circuit elements that represent everything from ZR's Marx generators to the load, and will simulate everything from the triggering of the Marxes to the delivery of current to the load.

\section{ACKNOWLEDGMENTS}

The authors gratefully acknowledge K. Androlewicz, D. Artery, W. Ballard, J. Barth, W. Beezhold, T. Bock, J. Boyes, E. Breden, R. Brockman, D. Dalton, D. Droemer, S. Downie, D. Fehl, J. Gergel, J. Gergel, Jr., C. Guthrie, R. Hanes-Michaud, E. Harlan, M. Harris, D. Jobe, K. Jones, M. Kernaghan, J. Lee, J. Lott, J. Lynch, M. K. Matzen, M. Mazarakis, D. McDaniel, G. R. McKee, J. McKenney, L. P. Mix, G. Mowrer, G. Olivas, D. Petmecky, S. Ploor, J. Porter, J. Powell, J. Puissant, L. Reynolds, D. Rice, C. Robinson, M. Roderick, T. Romero, R. Ross, M. Savage, L. Schneider, J.H. Seamen, W. Simpson, I. Smith, R. Starbird, K. Struve, M. Sullivan, J. Webb, L. Wilson, A. York, and our many other colleagues at Barth Electronics, C-Lec Plastics, EG\&G, ITT Corporation, Ktech Corporation, L-3 Communications, Mission Research Corporation, Prodyn Technologies, Sandia National Laboratories, Team Specialty Products Corporation, T\&M Research, Voss Scientific LLC, and 
Votaw Precision Technologies for invaluable contributions. Sandia is a multiprogram laboratory operated by Sandia Corporation, a Lockheed Martin Company, for the United States Department of Energy's National Nuclear Security Administration under Contract No. DE-AC04-94AL85000.

\section{APPENDIX A: ENERGY-CONSERVATION ERROR}

The energy-conservation error has been calculated for each of the TL simulations outlined in this article.

TL calculates the total energy delivered to a stack-MITL system using the voltage and current time histories at the four sets of water-insulated bi-plate transmission lines that drive the system. TL also calculates throughout the stackMITL system the total inductive energy, total capacitive energy, and total energy dissipated by resistances, as well as the total energy delivered to the load. The fractional difference between the total delivered energy, and the sum of the total inductive, capacitive, resistive, and load energies, is calculated as a function of time. For all the simulations described in this article, the fractional difference never exceeds $0.5 \%$.

\section{APPENDIX B: OPTIMUM RATIO OF A MITL'S GEOMETRIC IMPEDANCE TO THAT OF THE LOAD FOR AN IDEALIZED MITL-LOAD SYSTEM}

In this Appendix we consider the idealized MITL-load system outlined by Fig. 11. Reference [86] states that the efficiency of coupling electromagnetic power from such a MITL to its load is maximized when the load impedance equals the MITL's self-limited impedance. (Please see, for example, Fig. 5 of [86].) This statement assumes that all of the flow electrons launched in the MITL become, at the load, part of the current flowing through the load itself, and that none of the MITL-flow-electron current is lost.

We calculate here the optimum ratio of the MITL's geometric impedance (the impedance in the absence of electron emission, flow electrons, gap closure, etc.) to the load impedance, assuming none of the flow electrons contribute to the load current. This assumption is applicable to the MITL system of Figs. 2 and 3, where most of the electrons launched in the outer MITLs are lost upstream of the load. The electrons are lost in the vicinity of the double-post-hole convolute and inner MITL.

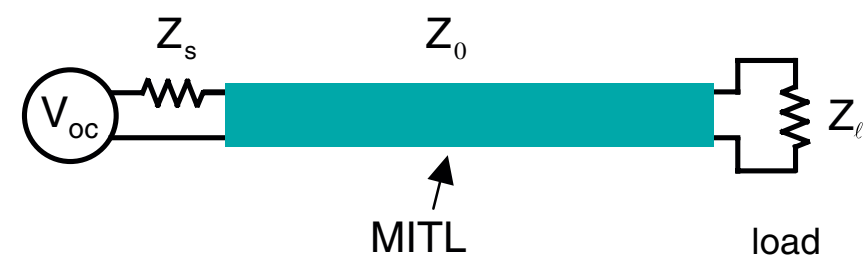

FIG. 11. (Color) Circuit model of an idealized MITL-load system. $V_{\text {oc }}$ is the open-circuit voltage that drives the system, $Z_{s}$ is the source impedance, $Z_{0}$ is the geometric impedance of the MITL, and $Z_{\ell}$ is the load impedance.
To calculate the optimum impedance ratio, we make the following simplifying assumptions:

$$
\begin{gathered}
I_{\ell}=I_{k}=I_{a}-I_{f}, \\
\frac{1}{2} L I_{a}^{2}=k, \\
L=Z_{0} \tau, \\
V_{a}=\frac{2}{3} Z_{0}\left(I_{a}^{2}-I_{k}^{2}\right)^{1 / 2}, \\
V_{a}=I_{\ell} Z_{\ell} .
\end{gathered}
$$

The quantity $I_{\ell}$ is the load current, $I_{k}$ is the MITL cathode current, $I_{a}$ is the MITL anode current, $I_{f}$ is the MITL-flowelectron current, $L$ is the total geometric MITL inductance, $k$ is a constant, $Z_{0}$ is the MITL's geometric impedance, $\tau$ is the one-way transit time of the MITL (in the absence of electron emission and flow electrons), $V_{a}$ is the total voltage across the MITL and load, and $Z_{\ell}$ is the load impedance.

Equation (B2) is valid when $L$ is near the value that optimizes, for power-pulse widths of interest, energy transfer from an accelerator with a given source impedance $Z_{s}$ to $L$. Equation (B4) is valid when the MITL-flow electrons are collisional, $I_{a} \gg I_{f}$, and $V_{a} \gtrsim 1 \mathrm{MV}$ [52]. Equations (B1)-(B5) assume that, near peak current, $I_{a}, I_{f}$, and $V_{a}$ are approximately constant throughout the length of the MITL. This assumption is valid when the two-way electromagnetic transit time of the MITL is much less than the current pulse width.

Combining Eqs. (B1)-(B5) we find numerically that the electromagnetic power at the load $P_{\ell}$ is maximized when $I_{f} / I_{a}=0.29$ and

$$
\frac{Z_{0}}{Z_{\ell}}=1.5
$$

The power $P_{\ell}$ is within $10 \%$ of its maximum value when $I_{f} / I_{a}=0.15$ and

$$
\frac{Z_{0}}{Z_{\ell}}=2.4
$$

It appears that for the idealized system illustrated by Fig. 11, under the conditions given by Eqs. (B1)-(B5), the peak power at the load is optimized when the impedance ratio $\left(Z_{0} / Z_{\ell}\right) \sim 2$. (Other optimum values are obtained for different sets of assumptions.)

It is clear there is a broad maximum in $P_{\ell}$ as a function of $Z_{0} / Z_{\ell}$; it is also clear that the presence of MITL gap closure would increase the optimum impedance ratio.

When $V_{a} \gtrsim 1 \mathrm{MV}$, the self-limited impedance of a MITL with collisional flow electrons (with fully developed collisional flow) is $0.588 Z_{0}$ [52]. Consequently, when Eqs. (B1)-(B5) are applicable, the optimum load imped- 
ance is comparable to the self-limited MITL impedance, as it is for the case considered in Ref. [86].

\section{APPENDIX C: EFFECTIVE PEAK PINCH CURRENT AND EFFECTIVE PINCH-IMPLOSION TIME}

All of the simulations discussed in this article assume that a $z$-pinch load can be modeled as an infinitely thin and perfectly stable cylindrical foil, and that the pinch convergence ratio is 10:1.

When comparing the results of simulations that do not produce mathematically similar pinch-current time histories, we find it useful to define an effective peak pinch current $I_{\text {eff }}$ and effective pinch-implosion time $\tau_{i, \text { eff }}$. Following Appendix C of Ref. [24] we define these quantities as follows:

$$
\begin{gathered}
I_{\mathrm{eff}}=2357\left(\frac{E_{k}}{\ell}\right)^{1 / 2}, \\
\tau_{i, \mathrm{eff}}=4.465 \frac{R}{v_{p}} .
\end{gathered}
$$

$E_{k}=m_{p} v_{p}^{2} / 2$ is the final kinetic energy of the idealized pinch described above, where $m_{p}$ is the total pinch mass and $v_{p}$ is the final implosion velocity; $\ell$ is the pinch length; and $R$ is the initial pinch radius. (The final kinetic energy and pinch velocity are those achieved when the pinch has imploded to $1 / 10$ of its initial radius.)

Equation $(\mathrm{C} 1)$ guarantees that two simulations with the same effective peak pinch current have the same final pinch kinetic energy per unit length. Equation (C2) guarantees that two simulations with the same initial pinch radius and effective implosion time have the same final pinch velocity.

[1] R. B. Spielman, W. A. Stygar, J. F. Seamen, F. Long, H. Ives, R. Garcia, T. Wagoner, K. W. Struve, M. Mostrom, I. Smith, P. Spence, and P. Corcoran, in Proceedings of the 11th IEEE International Pulsed Power Conference, edited by G. Cooperstein and I. Vitkovitsky (IEEE, Piscataway, NJ, 1997), p. 709.

[2] P. A. Corcoran, J. W. Douglas, I. D. Smith, P. W. Spence, W. A. Stygar, K. W. Struve, T. H. Martin, R. B. Spielman, and H.C. Ives, in Proceedings of the 11th IEEE International Pulsed Power Conference (Ref. [1]), p. 466.

[3] R. J. Garcia, H. C. Ives, K. W. Struve, R. B. Spielman, T.H. Martin, M.L. Horry, R. Wavrik, and T.F. Jaramillo, in Proceedings of the 11th IEEE International Pulsed Power Conference (Ref. [1]), p. 1614.

[4] H. C. Ives, D. M. Van De Valde, F. W. Long, J. W. Smith, R. B. Spielman, W. A. Stygar, R. W. Wavrick, and R. W. Shoup, in Proceedings of the 11th IEEE International Pulsed Power Conference (Ref. [1]), p. 1602.
[5] M. A. Mostrom, T. P. Hughes, R. E. Clark, W. A. Stygar, and R.B. Spielman, in Proceedings of the 11th IEEE International Pulsed Power Conference (Ref. [1]), p. 460.

[6] R. W. Shoup, F. Long, T. H. Martin, R. B. Spielman, W. A. Stygar, M. A. Mostrom, K. W. Struve, H. Ives, P. Corcoran, and I. Smith, in Proceedings of the 11th IEEE International Pulsed Power Conference (Ref. [1]), p. 1608.

[7] I. D. Smith, P. A. Corcoran, W. A. Stygar, T. H. Martin, R. B. Spielman, and R.W. Shoup, in Proceedings of the 11th IEEE International Pulsed Power Conference (Ref. [1]), p. 168.

[8] K. W. Struve, T. H. Martin, R. B. Spielman, W. A. Stygar, P. A. Corcoran, and J. W. Douglas, in Proceedings of the 11th IEEE International Pulsed Power Conference (Ref. [1]), p. 162.

[9] W. A. Stygar, R. B. Spielman, G. O. Allshouse, C. Deeney, D. R. Humphreys, H. C. Ives, F. W. Long, T. H. Martin, M. K. Matzen, D. H. McDaniel, C. W. Mendel, Jr., L. P. Mix, T. J. Nash, J. W. Poukey, J. J. Ramirez, T. W. L. Sanford, J.F. Seamen, D. B. Seidel, J. W. Smith, D. M. Van De Valde, R. W. Wavrik, P. A. Corcoran, J.W. Douglas, I. D. Smith, M. A. Mostrom, K. W. Struve, T. P. Hughes, R. E. Clark, R. W. Shoup, T. C. Wagoner, T. L. Gilliland, and B. Peyton, in Proceedings of the 11th IEEE International Pulsed Power Conference, Baltimore (Ref. [1]), p. 591.

[10] R. B. Spielman, C. Deeney, G. A. Chandler, M. R. Douglas, D. L. Fehl, M. K. Matzen, D. H. McDaniel, T. J. Nash, J. L. Porter, T. W. L. Sanford, J. F. Seamen, W. A. Stygar, K. W. Struve, S. P. Breeze, J. S. McGurn, J. A. Torres, D. M. Zagar, T. L. Gilliland, D. O. Jobe, J. L. McKenney, R. C. Mock, M. Vargas, T. Wagoner, and D. L. Peterson, Phys. Plasmas 5, 2105 (1998).

[11] R. B. Spielman and S. F. Lopez, Bull. Am. Phys. Soc. 32, 1786 (1987).

[12] P. Corcoran, J. Fockler, and D. Wake, Pulse Sciences Inc. Report No. PSI-FR-390-01, 1988.

[13] P. Corcoran, J. Fockler, H. Kishi, D. Wake, M. Christensen, and R. Sears, Pulse Sciences Inc. Report No. PSI-FR-390-05, 1988.

[14] P. Corcoran and J. Fockler, Pulse Sciences Inc. Report No. PSI-FR-1390-07, 1988.

[15] R. B. Spielman, R. J. Dukart, D. L. Hanson, B. A. Hammel, W. W. Hsing, M. K. Matzen, and J. L. Porter, in Dense Z Pinches: Proceedings of the 2nd International Conference on Dense Z Pinches, edited by N. R. Pereira, J. Davis, and N. Rostoker, AIP Conf. Proc. No. 195 (AIP, Melville, New York, 1989), p. 3.

[16] R. B. Spielman, P. Corcoran, J. Fockler, H. Kishi, and P.W. Spence, in Proceedings of the 7th IEEE International Pulsed Power Conference, edited by B. H. Bernstein and J. P. Shannon (IEEE, Piscataway, NJ, 1989), p. 445.

[17] T.H. Martin, J.P. VanDevender, D. L. Johnson, D. H. McDaniel, and M. Aker, in Proceedings of the International Topical Conference on Electron Beam Research and Technology, edited by Sandia National Labs (Sandia Labs, Albuquerque, NM, 1975), p. 450.

[18] W. W. Hsing, R. Coats, D. H. McDaniel, and R. B. Spielman, in Proceedings of the 5th IEEE International 
Pulsed Power Conference, edited by M. F. Rose and P. J. Turchi (IEEE, Piscataway, NJ, 1985), p. 704.

[19] T. P. Wright, D. H. McDaniel, R. W. Stinnett, W. W. Hsing, R. B. Spielman, M. A. Hedemann, P.W. Spence, K. E. Nielsen, J. Kishi, and R. G. Sears, in Proceedings of the 5th IEEE International Pulsed Power Conference (Ref. [18]), p. 493.

[20] R. B. Spielman, D. L. Hanson, M. A. Palmer, M. K. Matzen, T. W. Hussey, and J. M. Peek, J. Appl. Phys. 57, 830 (1985).

[21] P. Corcoran, L. Schlitt, P. Spence, and G. Proulx, Pulse Sciences Inc. Report No. PSI-FR-208, 1986.

[22] D. D. Bloomquist, R. W. Stinnett, D. H. McDaniel, J. R. Lee, A. W. Sharpe, J. A. Halbleib, L. G. Schlitt, P. W. Spence, and P. Corcoran, in Proceedings of the 6th IEEE International Pulsed Power Conference, edited by P. J. Turchi and B.H. Bernstein (IEEE, Piscataway, NJ, 1987), p. 310.

[23] W. N. Weseloh, in Proceedings of the 7th IEEE International Pulsed Power Conference, edited by B. H. Bernstein and J. P. Shannon (IEEE, Piscataway, NJ, 1989), p. 989.

[24] W. A. Stygar, M. E. Cuneo, D. I. Headley, H. C. Ives, R. J. Leeper, M. G. Mazarakis, C. L. Olson, J. L. Porter, T. C. Wagoner, and J.R. Woodworth, Phys. Rev. ST Accel. Beams 10, 030401 (2007).

[25] W. A. Stygar, W. E. Fowler, K. R. LeChien, F. W. Long, M. G. Mazarakis, G. R. McKee, J. L. McKenney, J. L. Porter, M. E. Savage, B.S. Stoltzfus, D. M. Van De Valde, and J.R. Woodworth, Phys. Rev. ST Accel. Beams 12, 030402 (2009).

[26] J.P. Martin, M.E. Savage, T.D. Pointon, and M. A. Gilmore, Phys. Rev. ST Accel. Beams 12, 030401 (2009).

[27] D. D. Hinshelwood, Naval Research Laboratory Memorandum Report No. 5185, 1983.

[28] M. L. Kiefer and M. M. Widner, in Proceedings of the 5th IEEE International Pulsed Power Conference (Ref. [18]), p. 685 .

[29] M. L. Kiefer, K. L. Shaw, K. W. Struve, M. M. Widner, and R. B. Spielman, SCREAMER, a pulsed-power design tool, user's guide for version 3.2.4.2 (2008).

[30] W. A. Stygar, H. C. Ives, T.C. Wagoner, J.A. Lott, V. Anaya, H. C. Harjes, J. P. Corley, R. W. Shoup, D. L. Fehl, G. R. Mowrer, Z. R. Wallace, R. A. Anderson, J. D. Boyes, J. W. Douglas, M. L. Horry, T. F. Jaramillo, D. L. Johnson, F. W. Long, T. H. Martin, D. H. McDaniel, O. Milton, M. A. Mostrom, D. A. Muirhead, T. D. Mulville, J. J. Ramirez, L. E. Ramirez, T. M. Romero, J. F. Seamen, J. W. Smith, C. S. Speas, R. B. Spielman, K. W. Struve, G. E. Vogtlin, D. E. Walsh, E. D. Walsh, M. D. Walsh, and O. Yamamoto, Phys. Rev. ST Accel. Beams 7, 070401 (2004).

[31] G. B. Frazier, in Proceedings of the 2nd IEEE International Pulsed Power Conference, edited by A. H. Guenther and M. Kristiansen (IEEE, Piscataway, NJ, 1979), p. 127.

[32] I. D. Smith, IEEE Trans. Plasma Sci. 25, 293 (1997).

[33] D. H. McDaniel, R. W. Stinnett, and I. D. Smith, Bull. Am. Phys. Soc. 25, 1017 (1980).

[34] P. Sincerny, D. Strachan, G. Frazier, C. Gilman, H. Helava, S. Wong, J. Banister, T. DaSilva, S. K. Lam, D. LePell, J.
Levine, R. Rodenburg, and T. Sheridan, in Proceedings of the 5th IEEE International Pulsed Power Conference (Ref. [18]), p. 151.

[35] T.P. Hughes and R.E. Clark, Mission Research Corporation Report No. MRC/ABQ-R-1875, 1998.

[36] T.P. Hughes and R.E. Clark, Mission Research Corporation Report No. MRC/ABQ-R-2005, 2000.

[37] T. P. Hughes, R. E. Clark, B. V. Oliver, R. A. St. John, and W. A. Stygar, Mission Research Corporation Report No. MRC/ABQ-R-2066, 2002.

[38] T. D. Pointon, W. A. Stygar, R. B. Spielman, H. C. Ives, and K. W. Struve, Phys. Plasmas 8, 4534 (2001).

[39] T. P. Hughes, R. E. Clark, B. V. Oliver, T. D. Pointon, and W.A. Stygar, in Proceedings of the 14th IEEE International Pulsed Power Conference, edited by M. Giesselmann and A. Neuber (IEEE, Piscataway, NJ, 2003), p. 622.

[40] C. W. Mendel, Jr., T. D. Pointon, M.E. Savage, D. B. Seidel, I. Magne, and R. Vézinet, Phys. Plasmas 13, 043105 (2006).

[41] D. V. Rose, D. R. Welch, T. P. Hughes, R. E. Clark, C. B. Mostrom, and W. A. Stygar, in Proceedings of the 16th IEEE International Pulsed Power Conference, edited by E. Schamiloglu and F. Peterkin (IEEE, Piscataway, NJ, 2007), p. 171.

[42] D. V. Rose, D. R. Welch, T. P. Hughes, R. E. Clark, and W. A. Stygar, Phys. Rev. ST Accel. Beams 11, 060401 (2008).

[43] D. V. Rose, D. R. Welch, R. E. Clark, E. A. Madrid, C. L. Miller, C. Mostrom, W. A. Stygar, M. E. Cuneo, C. A. Jennings, B. Jones, D. J. Ampleford, and K. W. Struve, in Proceedings of the 17th IEEE International Pulsed Power Conference (to be published).

[44] J.F. O'Hanlon, A User's Guide to Vacuum Technology (Wiley, New York, 1989).

[45] J. Blears, E. J. Greer, and J. Nightingale, in Advances in Vacuum Science and Technology (Pergamon, New York, 1960), p. 473.

[46] L. Holland, W. Steckelmacher, and J. Yarwood, Vacuum Manual (Spon, London, 1974).

[47] A. Roth, Vacuum Technology (North-Holland, New York, 1982).

[48] High Voltage Vacuum Insulation, edited by R. Latham (Academic, London, 1995), pp. 48-49.

[49] T. C. Wagoner, W. A. Stygar, H. C. Ives, T. L. Gilliland, R. B. Spielman, M. F. Johnson, P. G. Reynolds, J. K. Moore, R. L. Mourning, D. L. Fehl, K. E. Androlewicz, J.E. Bailey, R.S. Broyles, T.A. Dinwoodie, G.L. Donovan, M.E. Dudley, K. D. Hahn, A. A. Kim, J. R. Lee, R. J. Leeper, G. T. Leifeste, J. A. Melville, J. A. Mills, L.P. Mix, W.B.S. Moore, B.P. Peyton, J.L. Porter, G. A. Rochau, G. E. Rochau, M. E. Savage, J. F. Seamen, J. D. Serrano, A. W. Sharpe, R. W. Shoup, J. S. Slopek, C. S. Speas, K. W. Struve, D. M. Van De Valde, and R. M. Woodring, Phys. Rev. ST Accel. Beams 11, 100401 (2008).

[50] M. S. Di Capua and D. G. Pellinen, J. Appl. Phys. 50, 3713 (1979).

[51] P. A. Miller and C. W. Mendel, Jr., J. Appl. Phys. 61, 529 (1987).

[52] W. A. Stygar, T. C. Wagoner, H. C. Ives, P. A. Corcoran, 
M.E. Cuneo, J.W. Douglas, T.L. Gilliland, M. G. Mazarakis, J. J. Ramirez, J.F. Seamen, D. B. Seidel, and R. B. Spielman, Phys. Rev. ST Accel. Beams 9, 090401 (2006).

[53] Ya. Ya. Yurike, V.F. Puchkarev, and D. I. Proskurovskii, Sov. Phys. J. 16, 293 (1973).

[54] R. K. Parker, R. E. Anderson, and C. V. Duncan, J. Appl. Phys. 45, 2463 (1974).

[55] R. B. Baksht, B. A. Kablambaev, G. T. Razdobarin, and N. A. Ratakhin, Sov. Phys. Tech. Phys. 24, 689 (1979).

[56] D. D. Hinshelwood, IEEE Trans. Plasma Sci. 11, 188 (1983).

[57] R. W. Stinnett, M. A. Palmer, R. B. Spielman, and R. Bengston, IEEE Trans. Plasma Sci. 11, 216 (1983).

[58] R. W. Stinnett, G. R. Allen, H. P. Davis, T. W. Hussey, G. J. Lockwood, M. A. Palmer, L.E. Ruggles, A. Widman, H. N. Woodall, and R.D. Bengston, IEEE Trans. Electr. Insul. 20, 807 (1985).

[59] G. A. Mesyats and D. I. Proskurovsky, Pulsed Electrical Discharges in Vacuum (Springer-Verlag, New York, 1989).

[60] V. G. Kovalev, O.P. Pecherskii, Yu. M. Savel'ev, K. I. Tkachenko, V. I. Engel'ko, and M. Chlupek, Sov. Phys. Tech. Phys. 37, 813 (1992).

[61] P. Spence, K. Triebes, R. Genuario, and D. Pellinen, in Proceedings of the International Topical Conference on Electron Beam Research and Technology, edited by G. Yonas (Sandia National Laboratories, Albuquerque, NM, 1976) (Sandia National Laboratories Report No. SAND76-5122), p. 346.

[62] A.E. Blaugrund, G. Cooperstein, and S.A. Goldstein, Phys. Fluids 20, 1185 (1977).

[63] C.R. McClenahan, T.P. Wright, J.P. Quintenz, R. C. Backstrom, and P.W. Spence, Sandia National Laboratories Report No. SAND85-0740, 1985.

[64] M.E. Cuneo, R. M. Gilgenbach, and M. L. Brake, IEEE Trans. Plasma Sci. 15, 375 (1987).

[65] T. W. L. Sanford, J.A. Halbleib, J. W. Poukey, A. L. Pregenzer, R. C. Pate, C.E. Heath, R. Mock, G. A. Mastin, D. C. Ghiglia, T. J. Roemer, P. W. Spence, and G. A. Proulx, J. Appl. Phys. 66, 10 (1989).

[66] W. A. Stygar, S. E. Rosenthal, H. C. Ives, T. C. Wagoner, G. O. Allshouse, K. E. Androlewicz, G. L. Donovan, D. L. Fehl, M. H. Frese, T. L. Gilliland, M.F. Johnson, J. A. Mills, D. B. Reisman, P. G. Reynolds, C. S. Speas, R. B. Spielman, K. W. Struve, A. Toor, and E. M. Waisman, Phys. Rev. ST Accel. Beams 11, 120401 (2008).

[67] W. A. Stygar, G. A. Gerdin, and D. L. Fehl, Phys. Rev. E 66, 046417 (2002).

[68] W. A. Stygar, H. C. Ives, D. L. Fehl, M. E. Cuneo, M. G. Mazarakis, J. E. Bailey, G. R. Bennett, D. E. Bliss, G. A. Chandler, R. J. Leeper, M. K. Matzen, D. H. McDaniel, J. S. McGurn, J. L. McKenney, L. P. Mix, D. J. Muron, J. L. Porter, J. J. Ramirez, L. E. Ruggles, J. F. Seamen, W. W. Simpson, C. S. Speas, R. B. Spielman, K. W. Struve, J. A. Torres, R. A. Vesey, T. C. Wagoner, T. L. Gilliland, M. L. Horry, D. O. Jobe, S. E. Lazier, J. A. Mills, T. D. Mulville, J. H. Pyle, T. M. Romero, J. J. Seamen, and R. M. Smelser, Phys. Rev. E 69, 046403 (2004).

[69] D. L. Peterson, R.L. Bowers, K.D. McLenithan, C. Deeney, G. A. Chandler, R. B. Spielman, M. K. Matzen, and N. F. Roderick, Phys. Plasmas 5, 3302 (1998).

[70] C. J. Garasi, D. E. Bliss, T. A. Mehlhorn, B. V. Oliver, A. C. Robinson, and G.S. Sarkisov, Phys. Plasmas 11, 2729 (2004).

[71] Edmund P. Yu, M.E. Cuneo, M.P. Desjarlais, R. W. Lemke, D. B. Sinars, T. A. Haill, E. M. Waisman, G. R. Bennett, C. A. Jennings, T. A. Mehlhorn, T. A. Brunner, H. L. Hanshaw, J. L. Porter, W. A. Stygar, and L. I. Rudakov, Phys. Plasmas 15, 056301 (2008).

[72] J. P. Chittenden and C. A. Jennings, Phys. Rev. Lett. 101, 055005 (2008).

[73] R. W. Lemke, D. B. Sinars, E. M. Waisman, M. E. Cuneo, E. P. Yu, T. A. Haill, H. L. Hanshaw, T. A. Brunner, C. A. Jennings, W. A. Stygar, M. P. Desjarlais, T. A. Mehlhorn, and J. L. Porter, Phys. Rev. Lett. 102, 025005 (2009).

[74] D. R. Welch, D. V. Rose, R. E. Clark, C. B. Mostrom, W. A. Stygar, and R. J. Leeper, Phys. Rev. Lett. (to be published).

[75] P. A. Corcoran, B. A. Whitney, V.L. Bailey, I. D. Smith, W. A. Stygar, M. E. Savage, G. A. Rochau, J. E. Bailey, B. M. Jones, T. J. Nash, M. E. Sceiford, L. G. Schlitt, and J.W. Douglas, in Proceedings of the 17th IEEE International Pulsed Power Conference (to be published).

[76] D. H. McDaniel, M. G. Mazarakis, D.E. Bliss, J. M. Elizondo, H. C. Harjes, H. C. Ives, III, D. L. Kitterman, J.E. Maenchen, T.D. Pointon, S.E. Rosenthal, D.L. Smith, K. W. Struve, W. A. Stygar, E. A. Weinbrecht, D. L. Johnson, and J. P. Corley, in Proceedings of the 5th International Conference on Dense Z Pinches, edited by J. Davis, C. Deeney, and N. Pereira, AIP Conf. Proc. No. 651 (American Institute of Physics, Melville, NY, 2002), p. 23.

[77] M. E. Savage, L. F. Bennett, D. E. Bliss, W. T. Clark, R. S. Coats, J. M. Elizondo, K. R. LeChien, H. C. Harjes, J. M. Lehr, J. E. Maenchen, D. H. McDaniel, M. F. Pasik, T. D. Pointon, A.C. Owen, D. B. Seidel, D. L. Smith, B.S. Stoltzfus, K. W. Struve, W. A. Stygar, L. K. Warne, J. R. Woodworth, C. W. Mendel, K. R. Prestwich, R. W. Shoup, D. L. Johnson, J. P. Corley, K. C. Hodge, T. C. Wagoner, and P.E. Wakeland, in Proceedings of the 16th IEEE International Pulsed Power Conference, edited by E. Schamiloglu and F. Peterkin (IEEE, Piscataway, NJ, 2007), p. 979.

[78] K. R. LeChien, M. E. Savage, V. Anaya, D. E. Bliss, W. T. Clark, J. P. Corley, G. Feltz, J. E. Garrity, D. W. Guthrie, K. C. Hodge, J. E. Maenchen, R. Maier, K. R. Prestwich, K. W. Struve, W. A. Stygar, T. Thompson, J. Van Den Avyle, P.E. Wakeland, Z.R. Wallace, and J.R. Woodworth, Phys. Rev. ST Accel. Beams 11, 060402 (2008).

[79] M.E. Savage and B. S. Stoltzfus, Phys. Rev. ST Accel. Beams 12, 080401 (2009).

[80] D. V. Rose, D. R. Welch, E. A. Madrid, C. L. Miller, R. E. Clark, W. A. Stygar, K. Struve, P. A. Corcoran, and B. Whitney, in Dense $Z$ pinches: Proceedings of the 7th International Conference on Dense Z Pinches, edited by D. A. Hammer and B. R. Kusse, AIP Conf. Proc. No. 1088 (American Institute of Physics, Melville, NY, 2009), p. 263.

[81] D. V. Rose, D. R. Welch, E. A. Madrid, C. L. Miller, R. E. Clark, W. A. Stygar, M. E. Savage, G. A. Rochau, J. E. Bailey, T. J. Nash, M. E. Sceiford, K. W. Struve, P. A. 
Corcoran, and B. A. Whitney (unpublished).

[82] K. LeChien, W. Stygar, M. Savage, R. McKee, D. Bliss, P. Wakeland, D. Artery, M. Baremore, P. Jones, S. Roznowski, and S. White, in Proceedings of the 17th IEEE International Pulsed Power Conference (to be published).

[83] J. Lips, J. Garde, A. Owen, R. McKee, and W. Stygar, in Proceedings of the 17th IEEE International Pulsed Power Conference (to be published).

[84] B. Stoltzfus, K. LeChien, M. Savage, and W. Stygar, in Proceedings of the 17th IEEE International Pulsed Power Conference (to be published).

[85] K. R. LeChien, W. A. Stygar, M.E. Savage, P.E. Wakeland, V. Anaya, D. S. Artery, M. J. Baremore, D. E.
Bliss, R. Chavez, G. D. Coombs, J. P. Corley, P. A. Jones, A. K. Kipp, B. A. Lewis, J. A. Lott, J. J. Lynch, G. R. McKee, S. D. Ploor, K. R. Prestwich, S. A. Roznowski, S. D. White, and J. R. Woodworth (unpublished).

[86] J. P. VanDevender, G. W. Barr, J. T. Crow, S. A. Goldstein, D. H. McDaniel, K. F. McDonald, T.H. Martin, W. B. S. Moore, E. L. Neau, G. D. Peterson, J. F. Seamen, D. B. Seidel, R. B. Spielman, B. N. Turman, G. Yonas, and I. D. Smith, in Proceedings of the 4th International Topical Conference on High-Power Electron and Ion Beam Research and Technology (Beams '81), edited by H.J. Doucet and J. M. Buzzi (Ecole Polytechnique, Palaiseau, France, 1981), p. 725. 